Check for updates

Cite this: Soft Matter, 2017, 13,4808

Received 23rd December 2016, Accepted 16th June 2017

DOI: $10.1039 / \mathrm{c} 6 \mathrm{sm} 02867 \mathrm{e}$

rsc.li/soft-matter-journal

\section{From ice-binding proteins to bio-inspired antifreeze materials}

\author{
I. K. Voets (iD abc
}

\begin{abstract}
Ice-binding proteins (IBP) facilitate survival under extreme conditions in diverse life forms. IBPs in polar fishes block further growth of internalized environmental ice and inhibit ice recrystallization of accumulated internal crystals. Algae use IBPs to structure ice, while ice adhesion is critical for the Antarctic bacterium Marinomonas primoryensis. Successful translation of this natural cryoprotective ability into man-made materials holds great promise but is still in its infancy. This review covers recent advances in the field of ice-binding proteins and their synthetic analogues, highlighting fundamental insights into IBP functioning as a foundation for the knowledge-based development of cheap, bio-inspired mimics through scalable production routes. Recent advances in the utilisation of IBPs and their analogues to e.g. improve cryopreservation, ice-templating strategies, gas hydrate inhibition and other technologies are presented.
\end{abstract}

${ }^{a}$ Institute for Complex Molecular Systems, Eindhoven University of Technology, Post Office Box 513, 5600 MD Eindhoven, The Netherlands. E-mail: I.Voets@tue.nl ${ }^{b}$ Laboratory of Macromolecular and Organic Chemistry, Department of Chemical Engineering and Chemistry, Eindhoven University of Technology, Post Office Box 513, 5600 MD Eindhoven, The Netherlands

${ }^{c}$ Laboratory of Physical Chemistry, Department of Chemical Engineering and Chemistry, Eindhoven University of Technology, Post Office Box 513,

5600 MD Eindhoven, The Netherlands

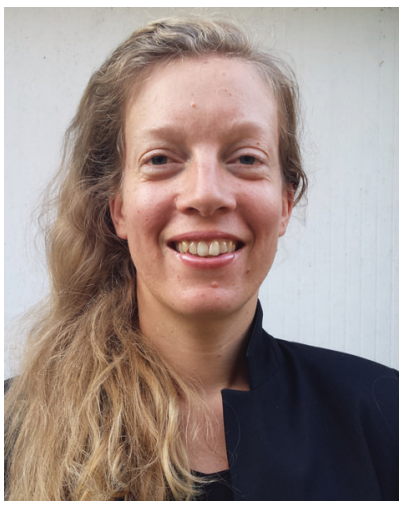

I. K. Voets
Dr Ilja K. Voets studied Molecular Sciences at Wageningen University in Wageningen, the Netherlands. She performed her $\mathrm{PhD}$ research on complex coacervate core micelles assembled from oppositely charged copolymers at the same university, after which she moved to the Adolphe Merkle Institute in Fribourg, Switzerland for a postdoctoral stay. In 2011 she was appointed as Assistant Professor at the Department of Chemical Engineering and Chemistry and the Institute for Complex Molecular Systems of Eindhoven University of Technology (TU/e). Currently she is Associate Professor in the Laboratory of Macromolecular and Organic chemistry and the Laboratory of Physical Chemistry of the TU/e, where she leads an independent research group focusing on self-organized and bioinspired soft matter.

\section{Introduction}

Polar fish produce ice-binding proteins to cope with the extremes of their natural habitat: ice-laden ocean waters with temperatures as low as $-1.9{ }^{\circ} \mathrm{C}$. ${ }^{1}$ Inspired by these cryoprotective biopolymers, chemists set out to develop efficient routes to prepare synthetic analogues in high yield, high purity, and low cost, for scientific research and potential application in e.g. food technology, ${ }^{2,3}$ agriculture, ${ }^{4,5}$ fishery, ${ }^{6,7}$ cryopreservation, ${ }^{8,9}$ petroleum industry, ${ }^{10-12}$ coating technology, ${ }^{13,14}$ and ice-templating. ${ }^{15}$

This review discusses the recent literature on native ice-binding proteins, including ice-nucleating proteins (INPs), ${ }^{16}$ as well as analogues thereof, focusing in particular on the outstanding questions of fundamental interest and the development of artificial, non-colligative antifreezes for a broad spectrum of innovative technologies. The umbrella term ice-binding proteins (IBPs) is utilized to denote all proteins that bind ice. Those IBPs that depress the hysteresis freezing point hFP below the hysteresis melting point hMP create a so-called 'thermal hysteresis gap' $\mathrm{TH}=\mathrm{hMP}-\mathrm{hFP}^{17}$ These are better known as antifreeze proteins (AFPs), antifreeze glycoproteins (AFGPs), or thermal hysteresis proteins (THP). Ice-nucleating proteins (INPs) reduce supercooling and induce freezing. This IBP subclass is thought to organize its surface waters into an ice-like template that favours ice nucleation as temperature decreases. ${ }^{16,18}$

\section{Structure and biological functions of ice-binding proteins}

Diverse life forms produce ice-binding proteins for protection against freezing. ${ }^{19,20}$ Early studies focused on $\mathrm{AF}(\mathrm{G}) \mathrm{Ps}$ isolated 
from natural sources, ${ }^{1,21,22}$ mostly fishes, purified by chromatography or (ice-)affinity purification. ${ }^{23}$ Nowadays most laboratories produce proteins and peptides either by recombinant expression in a suitable host like $E$. coli $^{24,25}$ or solid-phase peptide synthesis. ${ }^{26,27}$ An important advantage of these methods is the possibility to introduce site-specific mutations and engineer fusion proteins. ${ }^{25,28}$ This facilitates the introduction of fluorescent tags and proteins ${ }^{25}$ and studies on structure-property relationships, such as the composition of the ice-binding site. ${ }^{29,30}$ For example, the ice-binding sites of type I and III AFPs have been systematically altered to probe the relative importance of specific amino acids for ice-binding and activity. ${ }^{28,31}$ A delicate interplay of IBP/interactions seems likely, involving contributions of van der Waals interactions, ${ }^{32}$ hydrogen bonding, ${ }^{33}$ hydrophobic forces, ${ }^{24,26,32}$ and water structuring. ${ }^{34-36}$

\subsection{IBP classification}

Fishes, like Antarctic notothenioids, ${ }^{1,21}$ ocean pout, ${ }^{28,32,37}$ and winter flounder, ${ }^{26,38}$ express antifreeze glycoproteins (AFGPs) ${ }^{1,21}$ and type I-III antifreeze proteins (Fig. 1). AFGPs are categorized into 8 classes of descending size from AFGP1 with $M_{\mathrm{w}}=33.7 \mathrm{kDa}$ to AFGP8 with $M_{\mathrm{w}}=2.6 \mathrm{kDa} .^{21,39,40}$ AFGPs contain 4 to 50 tripeptide repeats of Ala-Ala-Thr (occasionally substituted by Pro-Ala-Thr in AFGPs 6-8) with the disaccharide galactose- $N$-acetylgalactosamine attached to each Thr. Type I AFPs are 3.3-4.5 kDa alanine-rich $\alpha$-helices found flounders, ${ }^{27,33}$ sculpins, ${ }^{24,33}$ and Alaskan plaice. ${ }^{33}$ An unusually large and potent type I AFP ('Maxi') coordinating over 400 waters was recently discovered in winter flounder. ${ }^{34}$ Its solution and XRD crystal structure were found to be in good agreement. ${ }^{41}$ The winter flounder and Alaskan plaice AFPs bind pyramidal planes of ice, the shorthorn sculpin AFP binds secondary prism planes, while Maxi adsorbs to multiple planes including the basal plane (Fig. 1). ${ }^{33,34,42}$ Type II AFPs from American herring, ${ }^{43}$ sea raven, ${ }^{44}$ poacher, ${ }^{45}$ and smelt ${ }^{46}$ are globular, cysteine-rich lectin-like proteins of 11-24 kDa that bind nonbasal planes. ${ }^{19,43}$ Type III AFPs from eel pout, ${ }^{47}$ ocean pout $^{28,32,37}$ and wolffish $^{6}$ are small, globular proteins of approx. 6-7 kDa without cysteins. Ocean pout type III AFP binds both the primary prism plane and a pyramidal plane of ice. ${ }^{28}$ Fish type IV AFP found in the longhorn sculpin does not appear to be used as IBP in its host. ${ }^{48}$

IBPs from bacteria, ${ }^{36}$ insects (Fig. 1) ${ }^{10}$ diatoms, ${ }^{49}$ plants, ${ }^{4,50}$ and fungi ${ }^{51}$ are often rich in $\beta$-solenoids and silk-like solenoids. ${ }^{19}$ By contrast, the $s f$ AFP from the snow flea contains six antiparallel polyproline type II coils. ${ }^{52}$ Recently, several xylomannan-based antifreeze glycolipids (AFGLs) were discovered in the darkling beetle Upis ceramboides. ${ }^{53}$ INPs are found in the hemolymph of insects ${ }^{54}$ and on bacterial membranes. ${ }^{3}$ The ice-nucleating protein (INP) from Pseudomonas syringae is modelled as a large

\begin{tabular}{lllll}
\hline & AFGP & Type I AFP & Type II AFP & Type III AFP \\
Mass (kg mol-1) Insect AFP \\
Representative structure \\
Origin \\
Crystal planes of \\
hexagonal ice (Ih)
\end{tabular}

Fig. 1 Antifreeze glycoproteins (AFGPs) from Antarctic Notothenioid fishes and antifreeze proteins (AFPs) from winter flounder (type I wfAFP, PDB: 1WFA), herring (type II hAFP, PDB: 2PY2), ocean pout (type III opAFP, 1HG7), and the beetle Dendroides canadensis (DAFP-1). Secondary structural elements are color-coded as follows: $\alpha$-helix (cyan), $\beta$-sheet (orange), and coil (gray). The ice crystal planes are color-coded: basal plane (pink), primary prism plane (yellow), secondary prism plane (green), and pyramidal plane (blue). Adapted from Oude Vrielink et al., Biointerphases 2016, 11, 018906 and Olijve et al., Proc. Natl. Acad. Sci. U. S. A., 2016, 113, 3740. 
$\beta$-helical 120-180 kDa protein anchored to the outer membrane with a highly repetitive central domain flanked by non-repetitive domains on either side. ${ }^{55}$ Other ice nucleation active Gram-negative bacteria are Pseudomonas fluorescens, Erwinia ananas, Erwinia uredovora, Erwinia herbicola, and Xanthomonas campestris. ${ }^{3}$

\subsection{Biological roles of IBPs}

Five distinct functional roles have been attributed to proteins that modulate ice nucleation and growth (Fig. 2). ${ }^{19,20,30}$ DeVries and others attributed $30 \%$ of the serum freezing point depression in Antarctic notothenioids to non-colligative effects arising from circulating AFGPs. ${ }^{1}$ This 'thermal hysteresis activity' of AF(G)Ps (Fig. 2A) is essential for the survival of 'freeze-avoidant' polar fish living in shallow waters. Within the TH gap, growth or melting of internalized ice crystals is prevented. ${ }^{17}$ These accumulate in organs like the spleen, and do not melt during the entire lifespan of the fish. ${ }^{17}$ Freeze-tolerant species are able to survive freezing. These use IBPs to inhibit ice recrystallization processes (Fig. 2E), during which ice crystals merge (accretive recrystallization), ${ }^{2}$ change shape (isomass recrystallization), ${ }^{2}$ or grow at the expense of smaller ones (migratory recrystallization). ${ }^{56}$ Various microorganisms likely produce IBPs to gain access to nutrient-rich environments. Algae ${ }^{29,57}$ and diatoms ${ }^{49}$ live in liquid-like cavities within sea ice created by secreted IBPs (Fig. 2B). ${ }^{49,57}$ The Antarctic bacterium Marinomonas primoryensis accesses oxygen and nutrients in the upper regions of sea lakes by binding to surface ice through an ice-binding domain at the tip of a MDa-large surface-bound
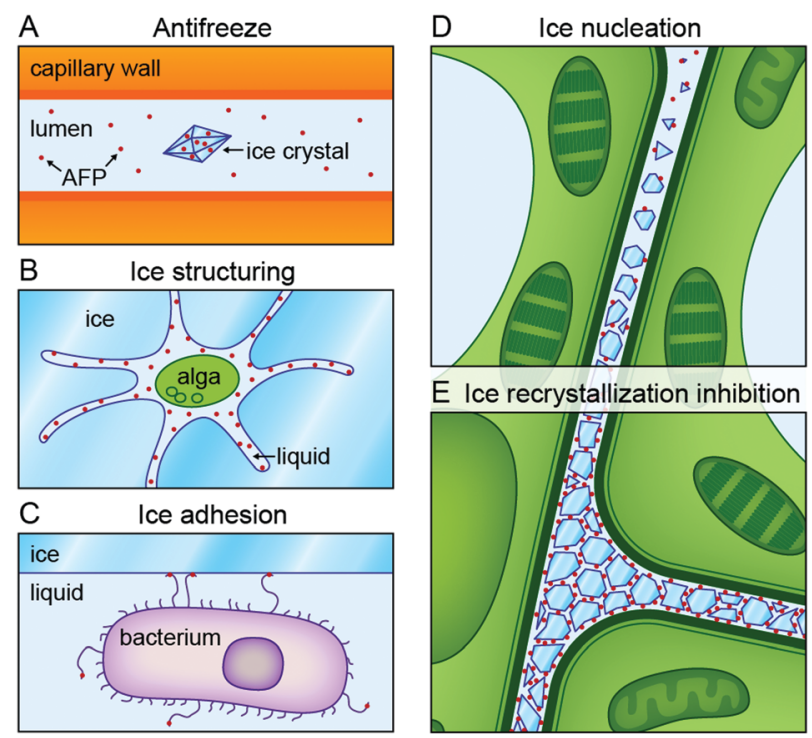

Fig. 2 Biological functions of ice-binding proteins (IBPS). (a) Antifreeze (glyco)proteins in 'freeze-avoiding' species lower the freezing point of bodily fluids to halt further growth of internalized ice crystals. (b) Secreted IBPs from microorganisms like algae create a liquid habitat for their host in sea ice. (c) The terminal ice-binding domain of adhesins on the surface of the bacterium Marinomas primoryensis facilitates attachment to ice on Antarctic lakes for access to oxygen and nutrients. (d) Ice nucleation proteins in freeze-tolerant species of e.g. plants locally trigger ice nucleation at high subzero temperatures. (e) Many IBPs inhibit ice recrystallization during which ice crystals grow, merge, or change shape. Reproduced from Oude Vrielink et al., Biointerphases, 2016, 11, 018906. adhesin (Fig. 2C) ${ }^{58,59}$ There is a growing interest in ice-nucleating proteins (INPs, Fig. 2D) from e.g. Pseudomonas syringae. ${ }^{3,60}$ INPs induce ice nucleation at undercoolings ranging from -5 to $-12{ }^{\circ} \mathrm{C}$ in plants. ${ }^{60}$ This enables pathogens to cause injuries in the epithelia of fruits and plants to gain food access. On the contrary, INPs can increase freeze-tolerance in e.g. bacteria and plants by protective extracellular freezing and utilisation of the released heat of fusion as heat source. ${ }^{60,61}$ In freeze-avoidant insects, ice-nucleating agents are removed or inactivated by complexation with IBPs. ${ }^{54,60,62}$

\section{IBP activity}

Various assays of hallmark features of IBPs have been developed to evaluate whether a newly discovered protein belongs to the class of IBPs and if so, measure its potency. Similarly, these are used to measure the effectiveness of IBP analogues. Quantitative assays and image analysis routines have been developed to accurately measure thermal hysteresis (TH) activity, ${ }^{63-66}$ ice recrystallization inhibition (IRI) activity, ${ }^{56,67,68}$ dynamic ice-shaping (DIS), ${ }^{69}$ and ice nucleation (IN) activity. ${ }^{70}$ Furthermore, ice-binding can be detected directly, albeit in a qualitative fashion, by ice-etching $^{33}$ and fluorescently based ice-plane affinity (FIPA) ${ }^{28}$ if IBPs are tagged with fluorescent proteins or dyes. ${ }^{33,71}$

\subsection{Antifreeze activity}

Antifreeze proteins are a subclass of IBPs that depress the hysteresis freezing point hFP below the hysteresis melting point hMP to create a so-called 'thermal hysteresis gap' $\mathrm{TH}=\mathrm{hMP}-\mathrm{hFP}^{17}$ This TH gap comprises two hysteresis intervals: a melting hysteresis interval $(\mathrm{MH})$ between hMP and the equilibrium freezing/melting point eqFMP, ${ }^{72,73}$ and a freezing hysteresis interval (FH) between hFP and eqFMP. Freezing point depression by colligative antifreezes, like ethanol and ethylene glycol, scales linearly with the solution osmolality. Using $\Delta T_{\mathrm{f}}=K_{\mathrm{F}} \times b \times i$, with the freezing point depression, $\Delta T_{\mathrm{f}}$, the cryoscopic constant, $K_{\mathrm{f}}\left(=1.853 \mathrm{~K} \mathrm{~kg} \mathrm{~mol}^{-1}\right.$ for water), the molality, $b$, and the van't Hoff factor, $i$ (=2 for $\mathrm{NaCl}$ ), we obtain $\Delta T_{\mathrm{f}} \sim 0.004{ }^{\circ} \mathrm{C}$ for $1 \mathrm{mM}$ $\mathrm{NaCl}$ in water. $\mathrm{AF}(\mathrm{G}) \mathrm{Ps}$ lower hFP in a non-colligative manner, which is much more effective. For example, $\mathrm{TH}=0.6{ }^{\circ} \mathrm{C}$ for type I $w$ AAFP and type III rQAE at $5 \mathrm{mg} \mathrm{mL}^{-1}$ and $3 \mathrm{mg} \mathrm{mL}^{-1}, 66$ while the colligative effect is not more than $\Delta T_{\mathrm{f}} \sim 0.002{ }^{\circ} \mathrm{C}$.

Thermal hysteresis ( $\mathrm{TH}$ ) activity is traditionally evaluated by nanolitre cryoscopy (also known as nanolitre osmometry) (1,74 $^{21,76}$ under conditions of very slow cooling of single ice crystals. ${ }^{75,76}$ Innovative microfluidic designs ${ }^{63,64}$ greatly facilitate sample handling and experimentation compared to traditional osmometers. An alternative method to determine TH activity termed 'sonocrystallization' affords high-throughput measurements of both the freezing and melting temperatures of IBP solutions. ${ }^{65,66}$ It utilizes ultrasound to trigger ice nucleation at a significant undercooling of typically $-6{ }^{\circ} \mathrm{C}$ corresponding to fast ice growth conditions. As $\mathrm{TH}$ activity is concentration dependent, ${ }^{77}$ $\zeta=(\mathrm{hMP}-\mathrm{hFP}) / \sqrt{ } / C_{\mathrm{AF}(\mathrm{G}) \mathrm{P}}$ has been introduced as a quantitative measure for TH activity. ${ }^{66,78}$ Maximal TH activities measured by cryoscopy range from $0.1-0.5{ }^{\circ} \mathrm{C}$ in apoplastic extracts from 
overwintering plants ${ }^{4,61}$ and $\sim 2{ }^{\circ} \mathrm{C}$ for $30-40 \mathrm{~g} \mathrm{~L}^{-1}$ protein in fish serum ${ }^{21,74}$ to $\sim 2$ to $13{ }^{\circ} \mathrm{C}$ for 10 -times lower concentrations in insect hemolymph. ${ }^{54} \mathrm{TH}$ activity can be improved upon addition of (sub)molar concentrations of small molecular solutes $^{79}$ and ions, ${ }^{20,80}$ conjugation $^{81}$ to or complexation ${ }^{82}$ with potentiating proteins ${ }^{82}$ or other ice-binding proteins ${ }^{81}$ and polymers, ${ }^{83,84}$ and IBS enlargement. ${ }^{85}$ However, salts like sodium borate can also inactivate AFGPs. ${ }^{74,86}$

\subsection{Ice recrystallization inhibition activity}

Ice recrystallization is a thermodynamically driven process, during which the ice grain boundary area per unit volume decreases. As this lowers the free energy of the system, it occurs spontaneously. There are three types of recrystallization processes: isomass, accretive, and migratory recrystallization. ${ }^{2}$ During isomass recrystallization, ice crystals change shape or internal structure, as irregular grain surfaces are rounded-off and ice crystal defects are reduced. During accretive recrystallization, two or more neighbouring crystals merge into one. During migratory recrystallization, also known as Ostwald ripening, large crystals grow at the expense of small ones with high radii of curvature at constant ice volume fraction, temperature, and pressure. IBPs already inhibit recrystallization at very low, micromolar concentrations. ${ }^{66}$ The IRI activity can be enhanced further by specific ions ${ }^{87}$ and hydrocolloids. ${ }^{88}$

Ice recrystallization inhibition (IRI) activity is determined by polarized optical microscopy (POM) in a so-called 'splat-assay, ${ }^{89}$ or 'sandwich assay', ${ }^{67}$ which probe the rate and extent of ice recrystallization in thin wafers of ice. Splat assays are typically performed in the presence of $>2 \mathrm{mM} \mathrm{NaCl}^{90}$ or 1-100 $\mathrm{mM}$ phosphate-buffered saline (PBS) buffer ${ }^{68}$ and sandwich assays in the presence of $18-45 \%$ sucrose. ${ }^{56,91}$ In a splat assay quantification of efficacy is based on measurements of the (time-evolution of the) mean (largest) grain size (M(L)GS). ${ }^{92}$ In a sandwich assay (Fig. 3), ${ }^{93}$ the inhibitory concentration $C_{\mathrm{i}}$, is taken as a quantitative measure for IRI activity. It demarcates the boundary between a high recrystallization rate $k_{\mathrm{d}}$ at low IBP concentration $C_{\mathrm{IBP}}$ and a very low $k_{\mathrm{d}}$ at high $C_{\mathrm{IBP}}{ }^{67}$

A direct comparison between the results of the two IRI assays is unfortunately hampered by differences in sample composition and assay conditions, such as nucleation temperature, annealing temperature, and cooling rate. Care must be taken when identifying antifreezes or inferring ice-binding from ice-structuring (vide infra) and IRI assays. Prism facets may also appear in the melt under mechanical pressure ${ }^{94}$ and inactive antifreezes also exhibit IRI when too little intercrystalline liquid is present. ${ }^{90}$ This is because virtually all impurities block ice recrystallization when forced to reside on ice grain boundaries. To exclude false positives, it is thus essential to employ a significant amount of osmolytes in an IRI assay to ensure a sufficiently high liquid volume fraction. ${ }^{90}$

\subsection{Ice plane affinity \& ice crystal morphology}

The morphology of ice crystals grown in IBP solutions differs from the flat disks of ice observed in pure water. Dynamic ice shaping (DIS) or ice faceting is typically probed under an optical microscope (Fig. 4) ${ }^{95}$ or fluorescence microscope ${ }^{69}$ under conditions

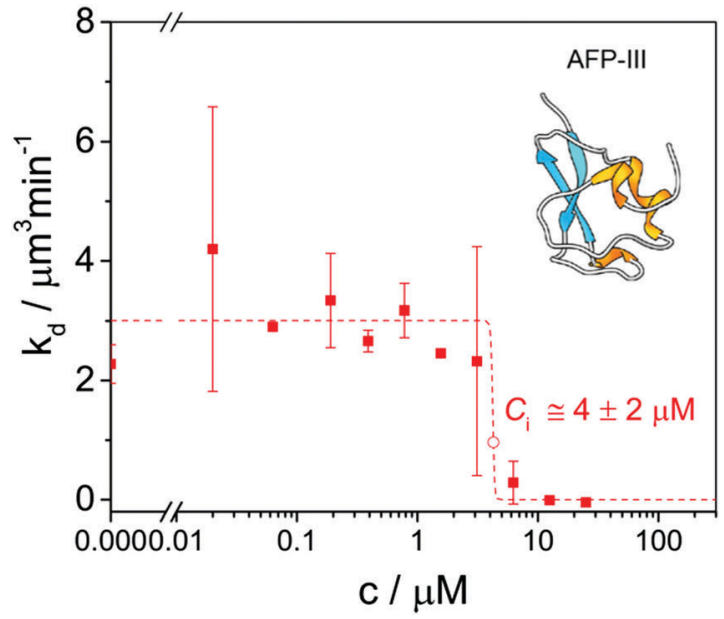

Fig. 3 A 'sandwich assay' of ice recrystallization inhibition (IRI) activity of type III opAFP in $30 \%$ sucrose at $-7{ }^{\circ} \mathrm{C}$ yields an inhibitory concentration $C_{\mathrm{i}}=4 \pm 2 \mu \mathrm{M}$. Reproduced (adapted) with permission from Olijve et al., Cryst. Growth Des., 2016, 16. Copyright (2014) American Chemical Society.

of slow ice growth or melting in (microfluidic) chambers utilized for TH assays by cryoscopy. The differential affinity of IBPs for the various crystal planes (prism, basal, pyramidal, see Fig. 1) leads to distinct (bipyramidal) structures within the thermal hysteresis gap when $T>$ hFP (Fig. 4, $c$-axis normal to the paper plane). ${ }^{95}$ These undergo burst growth along the $c$-axis (fish), ${ }^{75}$ perpendicular to the $c$-axis (insects), ${ }^{75}$ or along both the $c$ - and $a$-axis (plants) ${ }^{19}$ below the hysteresis freezing point hFP. Although simulations are able to reproduce these growth and burst morphologies, ${ }^{96}$ the molecular origin of these differences in affinity are not entirely understood. They may well be related to differences in the ice-binding sites (IBS) of AFPs, ${ }^{97}$ which vary in amino acid composition, structure ${ }^{98}$ and hydration. ${ }^{34,35}$ Some IBS display highly ordered arrays of specific amino acids, ${ }^{99}$ often threonines. ${ }^{20}$ A recombinant 96-residue polypeptide corresponding to the $P$. syringae INP segment Tyr $^{176}-$ Gly $^{273}$ shaped ice crystals into hexagonalbipyramids and exhibited a dose-dependent thermal hysteresis activity. $^{100}$

\subsection{Ice nucleation activity}

An energy barrier, also called the nucleation barrier, must be overcome to form a small, critical nucleus of ice in an aqueous solution that is supercooled below its equilibrium melting point (which equals its equilibrium freezing point). The metastable liquid state remains until the so-called 'supercooling point' or 'nucleation temperature' is reached. At this point, sufficiently large ice-like clusters form that grow into ice crystals. Ice-nucleating proteins limit supercooling and trigger ice nucleation at elevated subzero temperatures. This is probably because the ice-binding surface of INPs templates the organization of water molecules into an ice-like lattice which induces nucleation.

While the impact of IBPs on ice crystal growth is welldocumented, much less is known about heterogeneous ice nucleation by INPs ${ }^{3,54,60}$ and AFPs. ${ }^{101}$ Attempts to recombinantly express and subsequently purify membrane-associated INPs for 


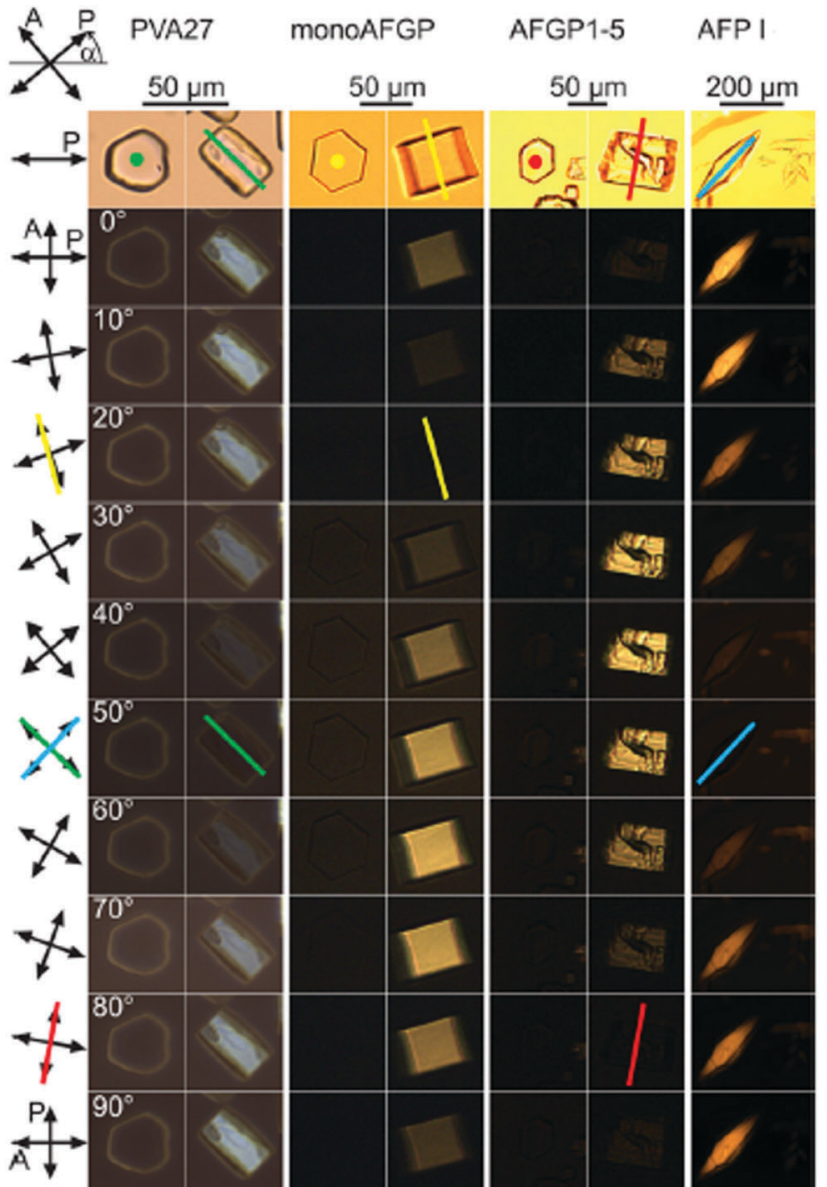

Fig. 4 Ice crystal habits in the presence of poly(vinyl alcohol) PVA27, a monosaccharide bearing synthetic AFGP analogue monoAFGP, natural AFGP1-5, and type I AFP from winter flounder AFP I. Bright field images without the analyser are shown in the top row. Subsequent rows shows ice crystals under crossed polarizers (A, P). The counterclockwise angle $\alpha$ of the polarizers relative to three o'clock is indicated. The colored lines (respectively dots), in the bright field and darkest polarized images indicate the direction of the $c$-axis (normal to the paper plane). Reproduced (adapted) with permission from Budke et al., Cryst. Growth Des., 2014, 14. Copyright (2014) American Chemical Society.

structure elucidation have failed thus far, since these large membrane proteins have a tendency to misfold and aggregate. ${ }^{60}$ Furthermore, the quantification of nucleation events is challenging experimentally, due to e.g. their stochastic nature. ${ }^{102}$ To ensure reasonable statistics, ice nucleation activity is probed in ensembles of droplets prepared by emulsification, ${ }^{3,103}$ or otherwise, ${ }^{70}$ by monitoring changes in scattering ${ }^{70,103}$ or heat effects ${ }^{104}$ upon ice formation.

\subsection{Comparison between TH and IRI activity}

A recent study compared $\mathrm{TH}$ and IRI activity measured by nanolitre cryoscopy, sonocrystallization, and POM for six different types of $\mathrm{AF}(\mathrm{G}) \mathrm{Ps}$ from different structural classes. No correlation was found between TH and IRI activity expressed in $\zeta$ and $C_{\mathrm{i}}{ }^{66}$ IBPs with high IRI activity may thus have low $\mathrm{TH}$ activity. Furthermore, TH activity determined by cryoscopy and sonocrystallization may differ by as much as 25 -fold. ${ }^{66}$ These variations must be related to differences in the operating conditions of the assays, the ice nucleation and growth characteristics (e.g., single crystal $v s$. polycrystalline), as well as the adsorption characteristics of the AF(G)Ps, like ice-plane affinity, accumulation rates ${ }^{63}$ etcetera. Indeed, previous experimental studies already showed a number of parameters including crystal size, ${ }^{47,105}$ ice volume fraction, ${ }^{106}$ annealing time, ${ }^{47,107}$ holding temperature, ${ }^{47}$ and cooling rate ${ }^{107}$ impact $\mathrm{TH}$ activity studied by cryoscopy. Furthermore, discrepancies were previously observed between $\mathrm{TH}$ values determined by different types of cryoscopy like nanoliter osmometry and capillary methods. ${ }^{54,108}$ Clearly, systematic studies under standardized conditions are required to elucidate precisely how $\mathrm{AF}(\mathrm{G})$ Ps work and IBP mimics should be tailored. Furthermore, experimental work should be complemented by computational studies to e.g. gain insight into IBS hydration ${ }^{109,110}$ and the interplay between various driving forces for ice-binding. ${ }^{111}$

\section{Physical underpinning of IBP activity}

\subsection{Adsorption-inhibition model}

In 1977, Raymond and DeVries introduced an adsorptioninhibition model to explain how $\mathrm{AF}(\mathrm{G})$ Ps block ice crystal growth in a non-colligative fashion. ${ }^{112}$ This step-pinning model proposed that AFPs bind irreversibly onto nascent ice crystals in the path of a growth step. The bound proteins thus force ice to advance between the adsorption sites. Above a critical surface density, this raises the curvature of the growing ice front and thus lowers the freezing point via the Gibbs-Thomson or Kelvin effect. ${ }^{77}$ Consequentially, a temperature interval known as the thermal hysteresis (TH) gap appears wherein steps are immobile and further ice growth is halted. ${ }^{112}$ Monte Carlo simulations on 3D ice crystals in the presence of TmAFP and type I wfAFP showed inhibition of ordered step growth. ${ }^{96}$ The step-pinning mechanism results in a square-root dependence of $\mathrm{TH}$ activity on IBP concentration, ${ }^{77}$ which is in line with numerous experiments. ${ }^{66}$

The original model was later refined by various others to take into account e.g. the anisotropic surface energy of ice, ${ }^{113}$ nonstepwise growth on rough prism planes, ${ }^{114,115}$ and the polymeric nature of IBPs. ${ }^{116}$ Future revisions are anticipated to discriminate between various inhibition scenarios ${ }^{96}$ and to achieve quantitative agreement between experiments ${ }^{117,118}$ and theory. ${ }^{119}$

\subsection{Molecular origin of ice-binding}

Research aiming to elucidate the mechanistic details of how IBPs work recently concentrated on two focal points: how do IBPs bind ice and how long do IBPs remain bound? Hydrogenbonding, ${ }^{33}$ ice-binding site (IBS) planarity ${ }^{22}$ (facilitating van der Waals contacts ${ }^{32}$ ), structural match with ice-lattice, ${ }^{22}$ inclusion of methyl functionalities within the ice lattice, ${ }^{32}$ and ice-like waters $^{34-36}$ have all been implicated as essential for docking of IBPs to ice. A combination of these factors is likely decisive, with variations in relative importance per IBP (class).

A number of experimental ${ }^{34,35}$ and computational ${ }^{109,110}$ studies have revealed clathrate-like or ice-like waters at the 
surface of IBPs. These are thought to mediate ice adhesion. ${ }^{36}$ An extensive hydrogen-bond network of bound waters was visible in the X-ray diffraction structure of a large, $\alpha$-helical type I antifreeze-protein (Maxi), ${ }^{34}$ not to be mistaken for the smaller $\alpha$-helical type I antifreeze-protein ( $w f$ AFP-1) from the same species. Interestingly, the structure suggests that the active dimer must bind via this network of organized waters, which emanates from the core of the dimer beyond the proteins' surface. The IBS of both dimerized monomers is buried in the interior and seemingly 'glued' together by the bound waters. Direct experimental evidence for IBP associated ice-like waters was obtained in a sum-frequency-generation (SFG) experiment performed at room temperature on type III antifreeze proteins from ocean pout (opAFP-3) adsorbed at the air-water interface (Fig. 5, left panel). ${ }^{35}$ An SFG spectrum reminiscent of ice was observed for wild-type opAFP-3 within a temperature interval ranging from $-2.5{ }^{\circ} \mathrm{C}$ up to room temperature. This characteristic ice-like signal was absent from spectra of an inactive T18N mutant and other non-ice-binding protein controls like bovine serum albumin (BSA). Interestingly, such ice-like waters were not visible either in the SFG spectra of the Dendroides Canadensis AFP (Fig. 5, right panel). ${ }^{120}$ This raises the intriguing questions: Which IBPs utilize ice-like surface waters for docking to ice? How does this work precisely? And which IBPs bind ice through a different mechanism? These questions will undoubtedly be subject of future work.

\subsection{Binding characteristics of IBPs}

A central premise in the adsorption-inhibition theory is irreversible binding of IBPs to ice. Although experimental evidence for the contrary has been reported, ${ }^{118,121}$ recent studies by fluorescence microscopy consistently demonstrated quasi-permanent attachment for TmAFP-GFP ${ }^{122,123}$ and type III AFP-GFP. ${ }^{25,123}$ On first sight, this seems contradictory to the concentration dependence of thermal hysteresis activity ${ }^{77}$ and the differences in activity of various types of $\mathrm{AF}(\mathrm{G})$ Ps measured under identical operating conditions

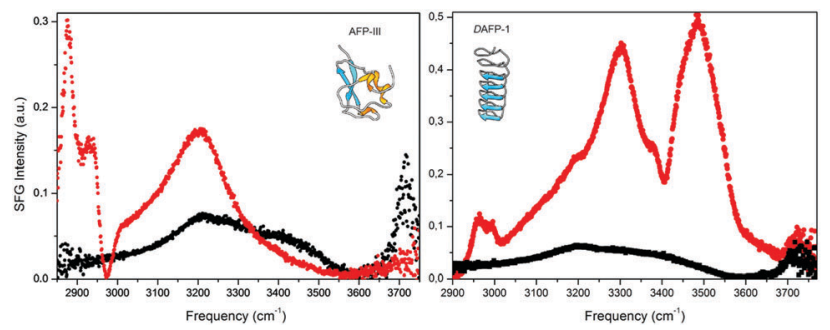

Fig. 5 Vibrational sum-frequency-generation (VSFG) spectra of pure water (right/left panel, black) and two AFP solutions: a $93 \mu \mathrm{M}$ type III AFP solution at $\mathrm{pH} 7.8$ (left panel, red) and a $20 \mu \mathrm{M}$ the Dendroides Canadensis AFP (DAFP-1) solution at pH 7.5 (right panel, red) at the air-water interface. (left) The strong and relatively narrow peak at $3.200 \mathrm{~cm}^{-1}$ for type III AFP (red) is attributed to ice-like waters and the spectral features at $<3.000 \mathrm{~cm}^{-1}$ to $\mathrm{CH}$ vibrations. (right) Contributions belonging to $\mathrm{CH}$-, $\mathrm{NH}-$, and $\mathrm{OH}$-stretching vibrations are visible for DAFP-1 (red) including sharp bands at $\sim 3300$ and $\sim 3485 \mathrm{~cm}^{-1}$. Reproduced (adapted) from Meister et al., Proc. Natl. Acad. Sci. U. S. A., 2014, 111(50), 17732 and reprinted (adapted) with permission from Meister et al., J. Phys. Chem. Lett., 2015, 1162. Copyright (2015) American Chemical Society. and concentrations. ${ }^{66}$ Consequently, irreversible attachment has been a subject of debate. To reconcile the apparently conflicting findings, two-step adsorption mechanisms were invoked, ${ }^{118}$ involving e.g. a surface-solution equilibrium close to the melting temperature and irreversible attachment at lower temperatures. ${ }^{77}$ But, experimental evidence of superheating for AFGPs $^{17,72}$ and AFPs like MpAFP and $\operatorname{TmAFP}^{73}$ contests this explanation. Sander and Tkachenko developed a 'kinetic pinning theory', ${ }^{115}$ which predicted a vanishing growth velocity as a function of the square root of the AFP concentration at a particular temperature. This is in line with the majority of experimental observations. Knight and DeVries also put forth kinetic arguments to rationalize the concentration-dependence and irreversible attachment of non-basal plane binding AFPs. ${ }^{124}$ The authors proposed that the concentration-dependence is a result of AFPs in solution that bind irreversibly onto newly exposed prism planes. These emanate from growing layers of ice, which appear due to secondary nucleation on the 'bare' basal planes. Below a critical size of these 'sensitive' planes, which is temperature-dependent, secondary nucleation on the basal plane ceases and crystal growth stops altogether. This argumentation is in agreement with recent fluorescence microscopy experiments demonstrating that AFPs in solution are essential to prevent growth of ice crystals grown from solutions of non-basal plane binding AFPs, while it is not required for insect AFPs that bind to both prism and basal planes. ${ }^{123}$ This suggests that insect AFPs cover all exposed ice crystal planes in a semi-permanent fashion, as demonstrated previously. ${ }^{25,122}$ Therefore, the AFP solution could be buffer-exchanged without loss of thermal hysteresis. ${ }^{123}$ Based on these findings, Braslavsky and co-workers propose that the TH activity of type III AFPs is related to their binding rate and solution concentration, while it is instead the ice surface concentration for TmAFP. ${ }^{64,123}$

\section{Synthetic analogues of ice-binding proteins}

An IBP can be discriminated from other proteins in the protein databank by a computational algorithm that recognises ice-binding sites. ${ }^{99}$ Notwithstanding, it is currently impossible to engineer a synthetic IBP analogue with an artificial, fully functional, IBS. De novo design of IBP mimics with high TH activity thus lies in the distant future. (Nonprotein) IRI active compounds, however, have been made successfully. ${ }^{68}$ The advantage of synthetic antifreezes is that these may be manufactured at lower cost, in higher yield, with higher purity and long-term stability.

\subsection{Small molecular IBP analogues}

Inspired by the high efficacy of AFGPs (Fig. 1) as ice recrystallization inhibitors, various groups set out to develop versatile strategies for the production of native glycopeptides ${ }^{125,126}$ and effective AFGPs analogues. ${ }^{126,127}$ These include various solution and solid phase approaches, like sequential native chemical ligation ${ }^{125,128}$ and click chemistry, ${ }^{129}$ as reviewed by others. ${ }^{39,126,127,130}$ This greatly 
facilitated structure-functions studies revealing the importance of various features including the nature of the carbohydrate moieties, ${ }^{131}$ molar mass, ${ }^{125}$ and an ordered secondary structure ${ }^{132}$ for activity.

To increase the stability and synthetic accessibility of AFGP mimics, Ben and co-workers prepared series of C-linked antifreeze glycoprotein analogues. The importance of peptide backbone structure, ${ }^{133}$ C-linker length between backbone and glycoside, ${ }^{134}$ and glycoside type ${ }^{131}$ were assayed. A few IRI-active but TH-defective compounds were discovered, which were further investigated for cryopreservation purposes. ${ }^{135,136}$ C-linked AFGP analogues with either too short, or too long linkers, ${ }^{134}$ or with glucose, mannose, or talose instead of galactose were (virtually) IRI inactive. ${ }^{131}$ This led to the proposal of a link between IRI activity and carbohydrate hydration. Incorporation of the monosaccharide galactose, with the highest hydration index and the lowest partial molar compressibility of the four incorporated monosaccharide pyranoses, yielded analogues with IRI activity, while the others (glucose, mannose, talose) did not. ${ }^{131,137}$ However, this trend did not hold for other carbohydratebased small molecule IRI inhibitors. ${ }^{135}$

The most potent IRI active small molecules reported to date are non-ice-binding amphiphilic small molecule carbohydrate derivatives and para-methoxyphenyl- $\beta$-D-glycosides. These reduce the mean ice grain size relative to PBS at millimolar concentrations, namely $22 \mathrm{mM}$ for the non-ionic surfactant $n$-octyl- $\beta$-D-galactopyranoside, ${ }^{138} 0.5 \mathrm{mM}$ for the hydrogelator $N$-octyl-D-gluconamide, ${ }^{138} \mathrm{IC}_{50}=16.3 \mathrm{mM}$ for $p$-methoxyphenyl $\beta$-D-glucopyranoside, ${ }^{68}$ and $\mathrm{IC}_{50}=14.8 \mathrm{mM}$ for $p$-bromophenyl $\beta$-D-glucopyranoside. ${ }^{68}$

\subsection{Polymeric IBP analogues}

The first synthetic polymer with IRI activity, but without measurable TH activity, was reported in 1995 by Knight and co-workers. ${ }^{90}$ Since, the $\mathrm{TH}^{139}$ and IRI ${ }^{91,92,140}$ activity of poly(vinyl alcohol) (PVA) and other polymers has been investigated by several laboratories. In-depth structure-function relations have not yet been established, but it has become clear that chain composition $^{92}$ (hydroxyl content, co-monomer content) and chain length matter, ${ }^{92,140}$ while chain architecture appears unimportant. ${ }^{93}$ Gibson and co-workers showed that PVA becomes IRI active for chain lengths $>10$ monomers, with higher activities for larger macromolecules, ${ }^{92}$ as previously observed by Inada et al. ${ }^{140}$ Similarly, the thermal hysteresis activity of native AFGPs, ${ }^{95}$ type I AFPs, ${ }^{34}$ and insect AFPs ${ }^{85}$ increases with increasing molecular weight. A direct comparison between linear PVA and PVA bottlebrushes (i.e., a graft copolymer with polymeric side-chains tethered to a linear backbone) revealed more or less equal IRI activity, ${ }^{93}$ while copolymerization with monomers like $\mathrm{N}$-vinylpyrrolidone or isopropenyl acetate reduces potency significantly. ${ }^{92}$ A comprehensive overview of IRI-activity of naturally occurring $\mathrm{AF}(\mathrm{G}) \mathrm{Ps}$ and their mimics (Fig. 6), ${ }^{95}$ categorizes PVA in the class of effective compounds $\left(10^{-1} \mu \mathrm{mol} \mathrm{L}{ }^{-1}<C_{\mathrm{i}}<10^{3} \mu \mathrm{mol} \mathrm{L}{ }^{-1}\right)$. It is surpassed by the very effective AFGPs $\left(C_{\mathrm{i}}<10^{-1} \mu \mathrm{mol} \mathrm{L}{ }^{-1}\right)$, but more potent than non-effective compounds $\left(C_{\mathrm{i}}>10^{3} \mu \mathrm{mol} \mathrm{L}^{-1}\right)$ like poly(ethylene glycol) (PEG), poly(aspartic acid) (PAspNa),

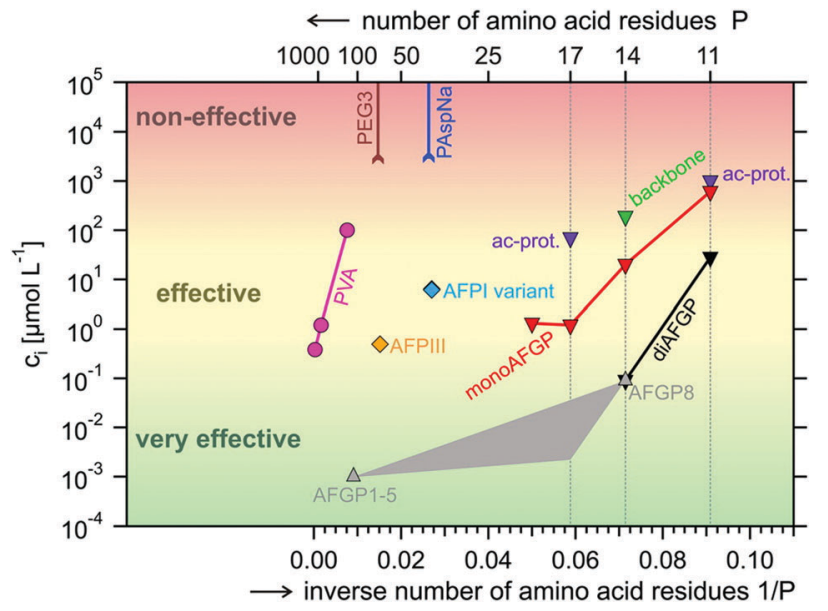

Fig. 6 Overview of the potency of natural and man-made inhibitors of ice recrystallization: natural type III AFPs (AFPIII), natural AFGPS (AFGP1-5, AFGP8), synthetic monosaccharide and disaccharide analogues of AFGPs (monoAFPG, diAFGP), an acetyl-protected monosaccharide peptide (ac-prot), polyvinyl alcohol (PVA), poly(ethylene glycol) (PEG), poly(aspartic acid) (PAspNa). Indicated is the IRI concentration $C_{i}$ as a function of the inverse number of amino acids (respectively weight-average degree of polymerization) $P^{-1}$ for (very) effective inhibitors and the maximum concentration tested without signs of activity $C_{\mathrm{LL}}$ for non-effective compounds. In grey the anticipated $C_{\mathrm{i}}$ for $P^{-1}$ intermediate between the values for AFGP1-5 and AFGP8 (no data are available). Reprinted with permission from Budke et al., Cryst. Growth Des., 2014, 14. Copyright (2014) American Chemical Society.

and other water-soluble polymers (including glycopolymers). These have weaker or no IRI activity. ${ }^{141}$

\subsection{Other analogues}

De novo polypeptides ${ }^{142,143}$ and peptoids ${ }^{144}$ with thermal hysteresis and IRI activity have been synthesized, but with lower activity than naturally occurring AFGPs. Laursen and co-workers published two TH active 34-mers with KAAK-motifs. ${ }^{142}$ Wierzbicki and co-workers reported a 43 residue alanine-lysine-rich peptide with a 32-times lower activity than the shorthorn sculpin (per weight basis). ${ }^{143}$ Rahaman et al. reported the total chemical synthesis of 4- to 8-mer saccharide subunits of the xylomannan motif of recently discovered non-protein antifreeze glycolipids (AFGLs). ${ }^{145}$

Davies and co-workers enhanced the activity of TmAFP by extension of its ice-binding site with additional coils. ${ }^{85}$ An optimum coil length was observed for the nine-coil construct with a maximal $\mathrm{TH}$ value of $6.5{ }^{\circ} \mathrm{C}$ at $0.7 \mathrm{mg} \mathrm{mL} \mathrm{m}^{-1}$. Lower activities were measured for the 10- and 11-coil constructs as these presumably have a larger lattice mismatch between their IBS and ice.

The inexpensive metallic salts zirconium(Iv) acetate (ZRA) and zirconium(Iv) acetate hydroxide (ZRHA) were reported to shape ice and display IRI activity, supposedly through a direct interaction with the ice-water interface. ${ }^{146,147}$ Similarly, Wang and co-workers reported IRI activity for graphene oxide (GO) due to a direct interaction between GO and ice, which was observed in molecular dynamics simulations. ${ }^{148}$ Interestingly, Drori and co-workers reported ice shaping into bipyramidal needles and inhibition of ice recrystallization by the synthetic dye Safranine $\mathrm{O}$ at millimolar concentrations. ${ }^{149}$ 


\section{Applications}

Control over the nucleation and growth of ice crystals is crucial for the survival of various species, ${ }^{16}$ atmospheric glaciation processes, ${ }^{18}$ and decisive for the structural integrity and properties of a broad range of water-based materials. ${ }^{15}$ This spurred interest in the large-scale production of fully synthetic non-colligative antifreezes for scientific and technological purposes. To this end, current hurdles to (commercial) application of IBPs, such as low yield, high cost, and consumer concerns must be overcome. ${ }^{150}$ The following sections highlight a number of application areas wherein IBPs and their IRI-active analogues may prove useful.

\subsection{Food technology and agriculture}

IBPs are attractive candidates for application in food technology and agriculture to e.g. boost cold hardiness, ${ }^{4,5}$ improve food quality, ${ }^{2,3}$ and enhance sensorial characteristics. ${ }^{151}$ In this field of research and technology, $\mathrm{AF}(\mathrm{G}) \mathrm{Ps}$ are commonly referred to as ice-structuring proteins (ISPs), to avoid negative connotations with toxic colligative antifreezes like ethylene glycol. ${ }^{152}$

Inhibition of ice recrystallization by IBPs used as foodstuff additives may enhance frozen food shelf-life ${ }^{2}$ and preserve smooth textures in ice cream. ${ }^{151}$ IBPs may prevent the formation of large ice crystals, which induce morphological and mechanical changes in ice cream and cellular damage in fruits. For example, type III AFP preserved the gel-forming functionality of food muscle proteins, ${ }^{153}$ AFGP reduced drip loss after thawing in lamb meat, ${ }^{154}$ and frozen dough treated with a recombinant type I AFP mimic showed better fermentation capacity. ${ }^{155}$ Inhibition of supercooling by INPs during freeze drying of foods may reduce refrigeration cost and shorten freezing times. ${ }^{156}$ Summarizing, IBPs that arrest ice recrystallization during production, frozen storage, transport, and thawing of complex food colloids may improve their sensory perception and raise consumer acceptance. ${ }^{2}$ Notwithstanding, commercial application has so far remained limited to ice cream. ${ }^{157}$

Several transgenic species of fishes, ${ }^{7}$ flies ${ }^{158}$ and crops $^{4}$ have been generated aiming to promote cold hardiness and frost resistance in e.g. salmon, ${ }^{7}$ Drosophila melanogaster ${ }^{158}$ spring wheat, ${ }^{159}$ and mice. ${ }^{160,161}$ Thus far however, the achieved freezing protection of a few degrees in transgenic plants is insufficient. Improvements are foreseen if high, targeted expression levels of potent AFPs in model plants (like Arabidopsis) and crops can be realized. ${ }^{5}$ Also, concerns have been raised about its environmental and sanitary impact. ${ }^{162,163}$ The US Food and Drug Administration (FDA) recently approved for the first time marketing of a genetically modified animal for food (AquAdvantage Salmon). ${ }^{157}$

\subsection{Biomedical applications}

Cryopreservation and hypothermic storage of cells, ${ }^{9}$ tissues, ${ }^{164}$ embryos $^{165}$ and organs ${ }^{164}$ has long been regarded as one of the most promising application areas of IBPs and their analogues. But, progress is much slower than aspired. ${ }^{9}$ In part, this is because the mechanisms of freezing damage are not fully understood, let alone how these are affected by cell type, tissue composition, and the presence of cryoprotectants (CPA).
Moreover, cryopreservation protocols are widely divergent (e.g., vitrification, slow-freezing) and adapted to a broad spectrum of cell types, which hampers a systematic comparison of results to elucidate the causes underlying success or failure of IBPs to improve preservation strategies.

Cellular damage during cryopreservation is a complex multifactorial process caused by $e . g$. intracellular ice formation, ${ }^{165,166}$ mechanical stress, ${ }^{164}$ freeze-dehydration, ${ }^{164}$ and ice recrystallization. ${ }^{166,167}$ These lead to cell death through cell rupture, ${ }^{168}$ necrosis $^{169}$ and apoptosis. ${ }^{158,170}$ Commonly employed cell penetrating CPA, like DMSO and glycerol, are effective but not without disadvantages: cell damage is not fully prevented, while the CPA may be toxic and must be removed after thawing prior to e.g. transplantation. ${ }^{164}$ This complication inspired widespread research into novel (non-)penetrating CPA like IBPs $^{9,165}$ and their analogues ${ }^{170}$ to minimize ice formation, ${ }^{169}$ to reduce the risk of ice nucleation, ${ }^{171}$ to prevent ice-induced damage to cell membranes and tissue matrices, ${ }^{172}$ to limit ice recrystallization, ${ }^{173}$ and to promote vitrification. ${ }^{171}$ However, their impact on hypothermic storage and cryopreservation has been discordant. ${ }^{9,170}$

Biological antifreezes had a negligible effect on the hypothermic storage of spinach thylakoids, ${ }^{168}$ and an adverse effect on the cryopreservation of bovine oocytes, ${ }^{174}$ equine embryos, ${ }^{175}$ and rat cardiac explant. ${ }^{176}$ For example, AFP type III did not preserve meiotic spindle organization of vitrified in vitro matured bovine oocytes. ${ }^{174}$ The deleterious effect of AFGPs on cryopreservation of rat cardiomyocytes was attributed to intracellular ice formation and cell lysis due to direct contact between the cells and needlelike ice spicules. ${ }^{177}$ In fact, type I AFPs may hold promise as chemical adjuvants in cryosurgery. ${ }^{178,179}$ By contrast, biological antifreezes protected (cell and plasma) membrane integrity and increased cell viability of bovine embryos ${ }^{172}$ and human hepatoma (HepG2) cells ${ }^{180}$ during hypothermic storage. Furthermore, IBPs improved the morphological integrity and post-thaw viability of cryopreserved probiotics, ${ }^{181}$ mouse oocytes, ${ }^{182}$ sea bream spermatozoa, ${ }^{183}$ red blood cells, ${ }^{184}$ mouse ovarian tissue, ${ }^{185}$ and rat hearts for transplantation. ${ }^{186}$ The addition of $100 \mu \mathrm{g} \mathrm{mL}^{-1}$ ocean pout type III AFP to semen extender (used to preserve the fertilizing ability of semen) improved the postthaw motility of spermatozoa chilled at $0-5{ }^{\circ} \mathrm{C} .{ }^{187}$

The observed variations in IBP performance on cryopreservation are due to differences in IBP activity, ${ }^{9}$ in cell and tissue types, ${ }^{164}$ in preservation conditions, ${ }^{169}$ and in freeze-thaw protocols, including CPA concentration as e.g. efficacy and toxicity are dose-dependent. ${ }^{165}$ As a consequence, consistently successful cryopreservation, especially of whole organs, remains a formidable challenge. ${ }^{164}$ Future studies should explore a combinatorial approach involving several types of CPAs, exerting both colligative and non-colligative protection, to address the multiplicity of causes of freeze injuries. ${ }^{9}$

The development of novel IBP analogues for cryopreservation has focused on the (scalable) synthesis of cryopreservants that are non-toxic, TH-inactive, and IRI-active. Various polymers, like poly(vinyl alcohol) PVA and carboxylated $\varepsilon$-poly-L-lysine (PLL), have been prepared and studied as non-penetrating CPAs. 
Matsumura and co-workers reported higher cryopreservation efficiency and lower cytotoxicity in the cryopreservation of murine L929 cells and rat bone marrow mesenchymal stem cells (RMSCs) for PLL compared to DMSO. ${ }^{188}$ Cell viability after thawing was found dependent on both PLL dose and the carbonyl mole fraction in the polyampholyte. PVA may assist cryopreservation by vitrification, since small amounts of PVA decreased the glycerol and DMSO concentrations required for vitrification of their solutions. ${ }^{171}$ Supplementing a $215 \mathrm{mg} \mathrm{mL}^{-1}$ hydroxyethyl starch (HES) solution with $1 \mathrm{mg} \mathrm{mL}^{-1}$ of the biocompatible non-penetrating polymer PVA $(9 \mathrm{kDa})$, increased human red blood cell (HRBC) recovery by $40 \%$ upon cryopreservation under rapid cooling. ${ }^{189}$ Ben and co-workers investigated the potency of several small molecule IRI inhibitors including carbohydrates as cell-penetrating CPA. ${ }^{135,166,173}$ One of the most potent C-linked AFGP analogues developed by Ben and co-workers was rapidly internalized in human embryonic liver cells. It showed no or little in vitro cytotoxicity and apoptotic death inhibition. Moreover, cell viability increased two-fold relative to cell medium (custodiol histidine-tryptophane-ketoglutarate solution), which was on par with $2.5 \%$ DMSO. ${ }^{190,191}$ Addition of the small molecule IRI inhibitors $p$-methoxyphenyl $(110 \mathrm{mM})$ and $\beta$-D-glucopyranoside $(30 \mathrm{mM})$ increased HRBC post-thaw integrity by $30-50 \%$ upon cryopreservation using slow cooling rates at $15 \%$ glycerol concentrations. $^{135}$ In this manner, the glycerol concentration required for effective cryopreservation may be lowered to reduce deglycerolization times, which is important in life-threatening situations warranting fast access for transfusions. Wang and co-workers reported an increase in cryopreserved horse sperm motility from $24.3 \%$ to $71.3 \%$ upon addition of $0.1 \mathrm{mg} \mathrm{mL}^{-1}$ graphene oxide, while addition of $3.5 \%$ glycerol (optimal amount) realized a motility of approx. $55 \% .{ }^{148}$ The hydrogelator $N$-octyl-D-gluconamide increased the infectivity and thermostability of candidate viral vectors for cancer vaccine development from vaccinia virus (VV) and herpes simplex virus type 1 (HSV-1), and furthermore improves the recovery of cryopreserved vesicular stomatitis virus (VSV). ${ }^{136}$

Biomedical application of $\mathrm{AF}(\mathrm{G}) \mathrm{Ps}$ in regenerative medicine and in therapeutic strategies against bacterial infections have been proposed recently. Suitable scaffolds for tissue engineering may be manufactured from material precursors supplemented with IBPs. ${ }^{15,192}$ Heisig et al. reported that a tick AFGP acts as an antivirulence factor preventing the formation of biofilms of several pathogens including Staphylococcus aureus both in vitro and in vivo. ${ }^{193}$

\subsection{Other applications}

The interest in IBPs and their analogues for application areas beyond food technology, agriculture, and biomedicine is steadily growing. Rather than providing an extensive overview, specific examples are presented to illustrate future prospects for e.g. materials science, ${ }^{15}$ petroleum industry, ${ }^{10-12}$ and climate control. ${ }^{194,195}$

Ice-templating is an interesting means to tailor the morphology of a broad range of materials including macroporous ceramics, ${ }^{192}$ polymers, and complex composites ${ }^{15}$ to produce catalysts, adsorbents, tissue engineering scaffolds, delivery systems, and strong yet light-weight materials, as recently reviewed by Deville. ${ }^{15}$ For example, porous carrier materials for nutrient and drug delivery, gastronomic applications, and scaffolds for tissue engineering can be manufactured using controlled unidirectional freezing (and subsequent freeze drying). ${ }^{196}$ As IBPs modulate ice crystal growth rates and habits, these may affect the size (distribution), shape and connectivity of the pores in the matrix.

As IBPs also impact the growth ${ }^{197}$ and morphology of crystals other than ice, ${ }^{198}$ they may prove useful as small molecular crystal growth modifiers. ${ }^{199}$ For example, gas hydrate inhibition by IBPs and their analogues has also become an area of considerable activity. ${ }^{10-12}$

Several studies on anti-icing and de-icing report that AFP surface-tethering may hinder icing and reduce ice adhesion to solid substrates. ${ }^{14,200}$ But, the opposite effect has been reported for aluminium surfaces functionalized with fish type III AFPs. ${ }^{201}$ A combined experimental and computational study on three AFPs (an insect AFP from the beetle Microdera punctipennis dzungarica) (MpdAFP), a bacterial AFP from Marinomonas primoryensis (MpAFP), and a type III fish AFP sheds light. ${ }^{13}$ It demonstrates that the orientation of MpdAFP on the surface is important (Fig. 7). Ice nucleation was promoted when the ice binding site of MpdAFP was exposed to liquid water (IBF). By
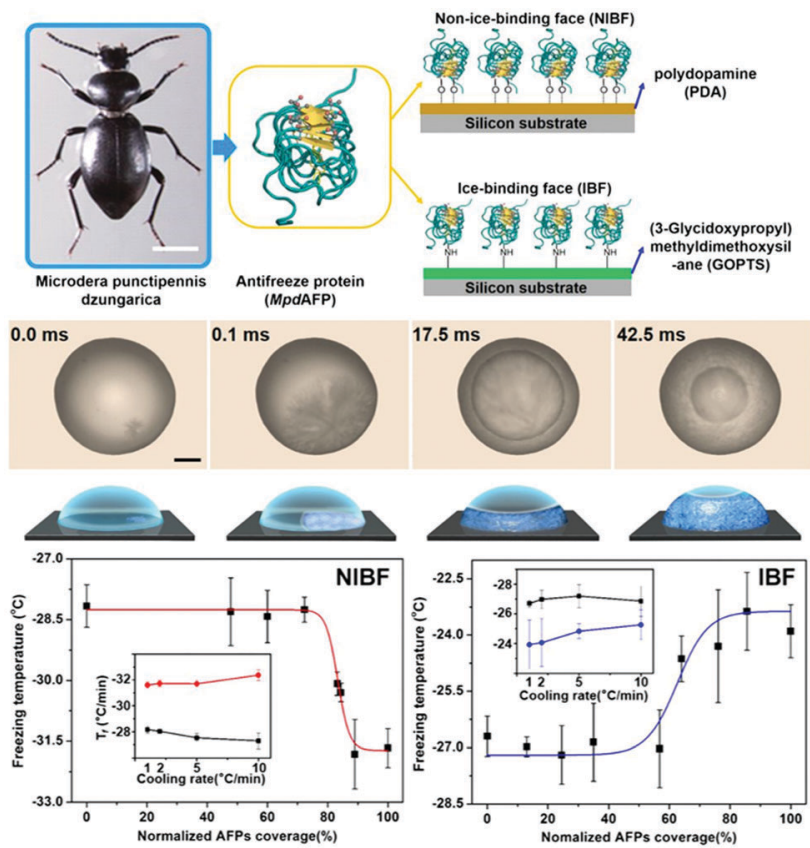

Fig. 7 (top) Schematic representation of the tethering of insect AFPs from Microdera punctipennis dzungarica (MpdAFPs) onto polydopamine (PDA) films and (3-glycidoxypropyl) methyldimethoxysilane (GOPTS) coated surfaces exposing respectively the non-ice-binding face (NIBF) and ice-binding face (IBF) of MpdAFPs. (middle) Droplet freezing is recorded by a high-speed camera, which reveals (bottom) MpdAFP coverage dependent suppression and facilitation of ice nucleation on the NIBF and IBF surfaces, respectively. Reproduced (adapted) from Liu et al., Proc. Natl. Acad. Sci. U. S. A., 2016, DOI: 10.1073/pnas.1614379114. 
contrast, ice nucleation was disfavoured in the opposite orientation with the non-ice binding face (NIBF) exposed to the solvent. This is in line with earlier work by Nutt and co-workers who proposed a dual function for the solvation waters of AFPs. ${ }^{110}$ These promote on the one hand recognition and binding of the ice binding site to ice. On the other hand, engulfment is prevented by perturbing waters in the solvation shell around the remainder of the protein.

Ice-nucleating agents including INPs receive widespread attention as factors that influence atmospheric glaciation processes and thus impact precipitation, cloud formation, and climate. ${ }^{194,195}$ INPs have been exploited for artificial snow production; for example, the commercial product Snomax ${ }^{\circledR}$ is based on freeze-dried nonviable cells of Pseudomonas syringae. ${ }^{3}$ Ice-nucleating proteins have also been utilized as a potent anchoring motif for cell surface display-applications including protein engineering, combinatorial library screening, vaccine development, biocatalysis, ${ }^{202}$ and bioremediation (see ref. 203 and 204 and refs therein).

\section{Concluding remarks}

Unveiling how Nature protects against freezing is a grand scientific challenge culminating in the development of powerful synthetic antifreezes for agrifood, materials science, coatings and biomedical applications. Great insights have been obtained in the structure and functioning of IBPs and their analogues, but, many open questions remain. To name but a few: what is the functional role of the various (inactive) isoforms of IBPs? Why are the most active isoforms sometimes least abundant $?^{76,205}$ What is the link between TH and IRI activity $?^{66,88,206}$ What is the relation between surface coverage $\mathrm{e}^{117}$ and activity? What causes the observed functional differences between IBPs? What is the relation between IBP structure, hydration and interaction with ice? How to design an AFGP analogue with higher IRI activity than its natural counterpart? Furthermore, the commercial potential of IBPs has remained largely unrealized despite great promise. Future experimental and computational studies should address these fundamental and technological challenges in a systematic manner. This will shed light on the relation between IBP (analogue) type, activity, and ice binding characteristics, which is essential for the knowledge-based development of potent bio-inspired mimics that can be manufactured in high yield at low cost for scientific purposes and successful commercialization.

\section{Acknowledgements}

This work was financially supported by the European Union (ERC-2014-StG Contract No. 635928), the Dutch Science Foundation (NWO ECHO Grant No. 712.016.002), and the Dutch Ministry of Education, Culture and Science (Gravity Program 024.001.035).

\section{Notes and references}

1 A. L. DeVries and D. E. Wohlschlag, Freezing resistance in some antarctic fishes, Science, 1969, 163, 1073-1075.
2 M. Hassas-Roudsari and H. D. Goff, Ice structuring proteins from plants: Mechanism of action and food application, Food Res. Int., 2012, 46, 425-436.

3 N. Cochet and P. Widehem, Ice crystallization by Pseudomonas syringae, Appl. Microbiol. Biotechnol., 2000, 54, 153-161.

4 R. Gupta and R. Deswal, Antifreeze proteins enable plants to survive in freezing conditions, J. Biosci., 2014, 39, 931-944.

5 J. G. Duman and M. J. Wisniewski, The use of antifreeze proteins for frost protection in sensitive crop plants, Environ. Exp. Bot., 2014, 106, 60-69.

6 M. Desjardins, N. R. Le Francois, G. L. Fletcher and P. U. Blier, High antifreeze protein levels in wolffish (Anarhichas lupus) make them an ideal candidate for culture in cold, potentially ice laden waters, Aquaculture, 2007, 272, 667-674.

7 H. M. Zbikowska, Fish can be first - advances in fish transgenesis for commercial applications, Transgenic Res., 2003, 12, 379-389.

8 H. J. Kim, et al., Marine Antifreeze Proteins: Structure, Function, and Application to Cryopreservation as a Potential Cryoprotectant, Mar. Drugs, 2017, 15, 27.

9 K. G. M. Brockbank, L. H. Campbell, E. D. Greene, M. C. G. Brockbank and J. G. Duman, Lessons from nature for preservation of mammalian cells, tissues, and organs, In Vitro Cell. Dev. Biol.: Anim., 2011, 47, 210-217.

10 C. M. Perfeldt, et al., Inhibition of Gas Hydrate Nucleation and Growth: Efficacy of an Antifreeze Protein from the Longhorn Beetle Rhagium mordax, Energy Fuels, 2014, 28, 3666-3672.

11 H. Zeng, L. D. Wilson, V. K. Walker and J. A. Ripmeester, Effect of antifreeze proteins on the nucleaton, growth, and the memory effect during tetrahydrofuran clathrate hydrate formation, J. Am. Chem. Soc., 2006, 128, 2844-2850.

12 D. Tonelli, C. J. Capicciotti, M. Doshi and R. N. Ben, Inhibiting gas hydrate formation using small molecule ice recrystallization inhibitors, $R S C A d v ., 2015$, 5, 21728-21732.

$13 \mathrm{~K}$. Liu, et al., Janus effect of antifreeze proteins on ice nucleation, Proc. Natl. Acad. Sci. U. S. A., 2016, 113, 14739-14744.

14 A. P. Esser-Kahn, V. Trang and M. B. Francis, Incorporation of Antifreeze Proteins into Polymer Coatings Using SiteSelective Bioconjugation, J. Am. Chem. Soc., 2010, 132, 13264-13269.

15 S. Deville, Ice-templating, freeze casting: beyond materials processing, J. Mater. Res., 2013, 28, 2202-2219.

16 J. G. Duman, Animal ice-binding (antifreeze) proteins and glycolipids: an overview with emphasis on physiological function, J. Exp. Biol., 2015, 218, 1846-1855.

17 P. A. Cziko, A. L. DeVries, C. W. Evans and C.-H. C. Cheng, Antifreeze protein-induced superheating of ice inside Antarctic notothenioid fishes inhibits melting during summer warming, Proc. Natl. Acad. Sci. U. S. A., 2014, 111, 14583-14588.

18 R. Pandey, et al., Ice-nucleating bacteria control the order and dynamics of interfacial water, Sci. Adv., 2016, 2, e1501630.

19 M. Bar Dolev, I. Braslavsky and P. L. Davies, in Annual Review of Biochemistry, Vol 85, Annual Review of Biochemistry, ed. R. D. Kornberg, 2016, pp. 515-542. 
20 A. S. Oude Vrielink, A. Aloi, L. L. C. Olijve and I. K. Voets, Interaction of ice binding proteins with ice, water and ions, Biointerphases, 2016, 11, 018906.

21 A. L. DeVries, S. K. Komatsu and R. E. Feeney, Chemical and Physical Properties of Freezing Point-depressing Glycoproteins from Antarctic Fishes, J. Biol. Chem., 1970, 245, 2901-2908.

22 D. S. C. Yang, et al., Identification of the ice-binding surface on a type III antifreeze protein with a "Flatness function" algorithm, Biophys. J., 1998, 74, 2142-2151.

23 K. Basu, L. A. Graham, R. L. Campbell and P. L. Davies, Flies expand the repertoire of protein structures that bind ice, Proc. Natl. Acad. Sci. U. S. A., 2015, 112, 737-742.

24 K. Fairley, et al., Type I shorthorn sculpin antifreeze protein Recombinant synthesis, solution conformation, and ice growth inhibition studies, J. Biol. Chem., 2002, 277, 24073-24080.

25 N. Pertaya, et al., Fluorescence microscopy evidence for quasi-permanent attachment of antifreeze proteins to ice surfaces, Biophys. J., 2007, 92, 3663-3673.

26 A. D. J. Haymet, L. G. Ward and M. M. Harding, Winter flounder "antifreeze" proteins: synthesis and ice growth inhibition of analogues that probe the relative importance of hydrophobic and hydrogen-bonding interactions, J. Am. Chem. Soc., 1999, 121, 941-948.

27 S. Lotze, et al., Communication: probing the absolute configuration of chiral molecules at aqueous interfaces, J. Chem. Phys., 2015, 143, 201101.

28 C. P. Garnham, et al., Compound ice-binding site of an antifreeze protein revealed by mutagenesis and fluorescent tagging, Biochemistry, 2010, 49, 9063-9071.

29 Y. Gwak, et al., An intracellular antifreeze protein from an Antarctic microalga that responds to various environmental stresses, FASEB J., 2014, 28, 4924-4935.

30 P. L. Davies, Ice-binding proteins: a remarkable diversity of structures for stopping and starting ice growth, Trends Biochem. Sci., 2014, 39, 548-555.

$31 \mathrm{~J}$. Baardsnes, et al., New ice-binding face for type I antifreeze protein, FEBS Lett., 1999, 463, 87-91.

32 E. I. Howard, et al., Neutron structure of type-III antifreeze protein allows the reconstruction of AFP-ice interface, J. Mol. Recognit., 2011, 24, 724-732.

33 C. A. Knight, C. C. Cheng and A. L. DeVries, Adsorption of alpha-helical antifreeze peptides on specific ice crystalsurface planes, Biophys. J., 1991, 59, 409-418.

34 T. Sun, F.-H. Lin, R. L. Campbell, J. S. Allingham and P. L. Davies, An Antifreeze Protein Folds with an Interior Network of More Than 400 Semi-Clathrate Waters, Science, 2014, 343, 795-798.

35 K. Meister, et al., Observation of ice-like water layers at an aqueous protein surface, Proc. Natl. Acad. Sci. U. S. A., 2014, 111, 17732-17736.

36 C. P. Garnham, R. L. Campbell and P. L. Davies, Anchored clathrate waters bind antifreeze proteins to ice, Proc. Natl. Acad. Sci. U. S. A., 2011, 108, 7363.

37 S. Lotze, L. L. C. Olijve, I. K. Voets and H. J. Bakker, Observation of Vibrational Energy Exchange in a Type-III Antifreeze Protein, J. Phys. Chem. B, 2014, 118, 8962-8971.
$38 \mathrm{~W}$. Gronwald, et al., NMR characterization of side chain flexibility and backbone structure in the type I antifreeze protein at near freezing temperatures, Biochemistry, 1996, 35, 16698-16704.

39 M. M. Harding, P. I. Anderberg and A. D. J. Haymet, 'Antifreeze' glycoproteins from polar fish, Eur. J. Biochem., 2003, 270, 1381-1392.

40 Y. Lin, A. L. Devries and J. G. Duman, Studies on structure and activity of low molecular-weight glycoproteins from antarctic fish, Biochem. Biophys. Res. Commun., 1972, 46, 87-92.

41 L. L. C. Olijve, et al., Solution structure of hyperactive type I antifreeze protein, RSC Adv., 2013, 3, 5903-5908.

42 G. K. Scott, P. L. Davies, M. A. Shears and G. L. Fletcher, Structural variations in the alanine-rich antifreeze proteins of the pleuronectinae, Eur. J. Biochem., 1987, 168, 629-633.

43 Y. Liu, et al., Structure and Evolutionary Origin of $\mathrm{Ca}^{2+}$-Dependent Herring Type II Antifreeze Protein, PLoS One, 2007, 2, e548.

$44 \mathrm{~W}$. Gronwald, et al., The solution structure of type II antifreeze protein reveals a new member of the lectin family, Biochemistry, 1998, 37, 4712-4721.

45 Y. Nishimiya, et al., Crystal structure and mutational analysis of $\mathrm{Ca}^{2+}$-independent type II antifreeze protein from longsnout poacher, Brachyopsis rostratus, J. Mol. Biol., 2008, 382, 734-746.

46 L. A. Graham, J. Y. Li, W. S. Davidson and P. L. Davies, Smelt was the likely beneficiary of an antifreeze gene laterally transferred between fishes, BMC Evol. Biol., 2012, 12, 1-13.

47 M. Takamichi, Y. Nishimiya, A. Miura and S. Tsuda, Effect of annealing time of an ice crystal on the activity of type III antifreeze protein, FEBS J., 2007, 274, 6469-6476.

48 S. Y. Gauthier, et al., A re-evaluation of the role of type IV antifreeze protein, Cryobiology, 2008, 57, 292-296.

49 M. Bayer-Giraldi, I. Weikusat, H. Besir and G. Dieckmann, Characterization of an antifreeze protein from the polar diatom Fragilariopsis cylindrus and its relevance in sea ice, Cryobiology, 2011, 63, 210-219.

50 M. Smallwood, et al., Isolation and characterization of a novel antifreeze protein from carrot (Daucus carota), Biochem. J., 1999, 340, 385-391.

$51 \mathrm{H}$. Kondo, et al., Ice-binding site of snow mold fungus antifreeze protein deviates from structural regularity and high conservation, Proc. Natl. Acad. Sci. U. S. A., 2012, 109, 9360-9365.

52 B. L. Pentelute, et al., X-ray structure of snow flea antifreeze protein determined by racemic crystallization of synthetic protein enantiomers, J. Am. Chem. Soc., 2008, 130, 9695-9701.

53 K. R. Walters, A. S. Serianni, T. Sformo, B. M. Barnes and J. G. Duman, A nonprotein thermal hysteresis-producing xylomannan antifreeze in the freeze-tolerant Alaskan beetle Upis ceramboides, Proc. Natl. Acad. Sci. U. S. A., 2009, 106, 20210-20215.

54 J. G. Duman, Antifreeze and ice nucleator proteins in terrestrial arthropods, Annu. Rev. Physiol., 2001, 63, 327-357. 
55 S. P. Graether and Z. C. Jia, Modeling Pseudomonas syringae ice-nucleation protein as a beta-helical protein, Biophys. J., 2001, 80, 1169-1173.

56 L. L. C. Olijve, A. S. Oude Vrielink and I. K. Voets, A Simple and Quantitative Method to Evaluate Ice Recrystallization Kinetics Using the Circle Hough Transform Algorithm, Cryst. Growth Des., 2016, 16, 4190-4195.

57 J. A. Raymond, Algal ice-binding proteins change the structure of sea ice, Proc. Natl. Acad. Sci. U. S. A., 2011, 108, E198-E198.

58 T. D. R. Vance, et al., $\mathrm{Ca}^{2+}$-stabilized adhesin helps an Antarctic bacterium reach out and bind ice, Biosci. Rep., 2014, 34, 357-368.

59 M. Bar Dolev, R. Bernheim, S. Guo, P. L. Davies and I. Braslavsky, Putting life on ice: bacteria that bind to frozen water, J. R. Soc., Interface, 2016, 13, 20160210.

60 K. E. Zachariassen and E. Kristiansen, Ice nucleation and antinucleation in nature, Cryobiology, 2000, 41, 257-279.

61 M. Griffith and M. W. F. Yaish, Antifreeze proteins in overwintering plants: a tale of two activities, Trends Plant Sci., 2004, 9, 399-405.

$62 \mathrm{~J}$. Duman, The inhibition of ice nucleators by insect antifreeze proteins is enhanced by glycerol and citrate, J. Comp. Physiol., B, 2002, 172, 163-168.

63 R. Drori, Y. Celik, P. L. Davies and I. Braslavsky, Icebinding proteins that accumulate on different ice crystal planes produce distinct thermal hysteresis dynamics, J. R. Soc., Interface, 2014, 11, 1-10.

64 R. Drori, P. L. Davies and I. Braslavsky, Experimental correlation between thermal hysteresis activity and the distance between antifreeze proteins on an ice surface, RSC Adv., 2015, 5, 7848-7853.

65 A. Gaede-Koehler, A. Kreider, P. Canfield, M. Kleemeier and I. Grunwald, Direct Measurement of the Thermal Hysteresis of Antifreeze Proteins (AFPs) Using Sonocrystallization, Anal. Chem., 2012, 84, 10229-10235.

66 L. L. C. Olijve, et al., Blocking rapid ice crystal growth through nonbasal plane adsorption of antifreeze proteins, Proc. Natl. Acad. Sci. U. S. A., 2016, 113, 3740-3745.

67 C. Budke, C. Heggemann, M. Koch, N. Sewald and T. Koop, Ice Recrystallization Kinetics in the Presence of Synthetic Antifreeze Glycoprotein Analogues Using the Framework of LSW Theory, J. Phys. Chem. B, 2009, 113, 2865-2873.

68 S. Abraham, et al., Quantitative Analysis of the Efficacy and Potency of Novel Small Molecule Ice Recrystallization Inhibitors, Cryst. Growth Des., 2015, 15, 5034-5039.

69 M. Bar-Dolev, Y. Celik, J. S. Wettlaufer, P. L. Davies and I. Braslavsky, New insights into ice growth and melting modifications by antifreeze proteins, J. R. Soc., Interface, 2012, 9, 3249-3259.

70 C. Budke and T. Koop, BINARY: an optical freezing array for assessing temperature and time dependence of heterogeneous ice nucleation, Atmos. Meas. Tech., 2015, 8, 689-703.

71 K. Basu, et al., Determining the Ice-binding Planes of Antifreeze Proteins by Fluorescence-based Ice Plane Affinity, Journal of Videotape Experiments, 2014, e51185.
72 C. A. Knight and A. L. Devries, Melting inhibition and superheating of ice by an antifreeze glycopeptide, Science, 1989, 245, 505-507.

73 Y. Celik, et al., Superheating of ice crystals in antifreeze protein solutions, Proc. Natl. Acad. Sci. U. S. A., 2010, 107, 5423-5428.

74 A. L. DeVries, Glycoproteins as biological antifreeze agents in antarctic fishes, Science, 1971, 172, 1152-1155.

75 A. J. Scotter, et al., The basis for hyperactivity of antifreeze proteins, Cryobiology, 2006, 53, 229-239.

76 C. B. Marshall, G. L. Fletcher and P. L. Davies, Hyperactive antifreeze protein in a fish, Nature, 2004, 429, 153.

77 E. Kristiansen and K. E. Zachariassen, The mechanism by which fish antifreeze proteins cause thermal hysteresis, Cryobiology, 2005, 51, 262-280.

78 A. Haji-Akbari, Rating antifreeze proteins: not a breeze, Proc. Natl. Acad. Sci. U. S. A., 2016, 113, 3714-3716.

79 N. Li, C. A. Andorfer and J. G. Duman, Enhancement of insect antifreeze protein activity by solutes of low molecular mass, J. Exp. Biol., 1998, 201, 2243-2251.

80 E. Kristiansen, S. A. Pedersen and K. E. Zachariassen, Salt-induced enhancement of antifreeze protein activity: a salting-out effect, Cryobiology, 2008, 57, 122-129.

81 O. Can and N. B. Holland, Utilizing Avidity To Improve Antifreeze Protein Activity: A Type III Antifreeze Protein Trimer Exhibits Increased Thermal Hysteresis Activity, Biochemistry, 2013, 52, 8745-8752.

82 D. W. Wu and J. G. Duman, Activation of antifreeze proteins from larvae of the beetle dendroides-canadensis, J. Comp. Physiol., B, 1991, 161, 279-283.

83 C. A. Stevens, R. Drori, S. Zalis, I. Braslavsky and P. L. Davies, Dendrimer-Linked Antifreeze Proteins Have Superior Activity and Thermal Recovery, Bioconjugate Chem., 2015, 26, 1908-1915.

84 O. Can and N. B. Holland, Conjugation of Type I Antifreeze Protein to Polyallylamine Increases Thermal Hysteresis Activity, Bioconjugate Chem., 2011, 22, 2166-2171.

85 C. B. Marshall, M. E. Daley, B. D. Sykes and P. L. Davies, Enhancing the activity of a beta-helical antifreeze protein by the engineered addition of coils, Biochemistry, 2004, 43, 11637-11646.

86 S. Ebbinghaus, et al., Antifreeze Glycoprotein Activity Correlates with Long-Range Protein-Water Dynamics, J. Am. Chem. Soc., 2010, 132, 12210-12211.

87 A. Leiter, et al., Influence of heating temperature, pressure and $\mathrm{pH}$ on recrystallization inhibition activity of antifreeze protein type III, J. Food Eng., 2016, 187, 53-61.

88 V. Gaukel, A. Leiter and W. E. L. Spiess, Synergism of different fish antifreeze proteins and hydrocolloids on recrystallization inhibition of ice in sucrose solutions, J. Food Eng., 2014, 141, 44-50.

89 C. A. Knight, J. Hallett and A. L. Devries, Solute effects on ice recrystallization - an assessment technique, Cryobiology, 1988, 25, 55-60.

90 C. A. Knight, D. Y. Wen and R. A. Laursen, Nonequilibrium antifreeze peptides and the recrystallization of ice, Cryobiology, 1995, 32, 23-34. 
91 C. Budke and T. Koop, Ice recrystallization inhibition and molecular recognition of ice faces by poly(vinyl alcohol), ChemPhysChem, 2006, 7, 2601-2606.

92 T. Congdon, R. Notman and M. I. Gibson, Antifreeze (Glyco)protein Mimetic Behavior of Poly(vinyl alcohol): Detailed Structure Ice Recrystallization Inhibition Activity Study, Biomacromolecules, 2013, 14, 1578-1586.

93 L. L. C. Olijve, M. M. R. M. Hendrix and I. K. Voets, Influence of Polymer Chain Architecture of Poly(vinyl alcohol) on the Inhibition of Ice Recrystallization, Macromol. Chem. Phys., 2016, 217, 951-958.

94 M. Maruyama, Roughening transition of prism faces of ice crystals grown from melt under pressure, J. Cryst. Growth, 2005, 275, 598-605.

95 C. Budke, et al., Quantitative Efficacy Classification of Ice Recrystallization Inhibition Agents, Cryst. Growth Des., 2014, 14, 4285-4294.

96 B. Wathen, M. Kuiper, V. Walker and Z. C. Jia, A new model for simulating 3-D crystal growth and its application to the study of antifreeze proteins, J. Am. Chem. Soc., 2003, 125, 729-737.

97 C. S. Strom, X. Y. Liu and Z. C. Jia, Antifreeze proteininduced morphological modification mechanisms linked to ice binding surface, J. Biol. Chem., 2004, 279, 32407-32417.

98 F. Corzana, et al., Serine versus threonine glycosylation: the methyl group causes a drastic alteration on the carbohydrate orientation and on the surrounding water shell, J. Am. Chem. Soc., 2007, 129, 9458-9467.

99 A. C. Doxey, M. W. Yaish, M. Griffith and B. J. McConkey, Ordered surface carbons distinguish antifreeze proteins and their ice-binding regions, Nat. Biotechnol., 2006, 24, 852-855.

100 Y. Kobashigawa, et al., A part of ice nucleation protein exhibits the ice-binding ability, FEBS Lett., 2005, 579, 1493-1497.

101 P. W. Wilson, K. E. Osterday, A. F. Heneghan and A. D. J. Haymet, Type I Antifreeze Proteins Enhance Ice Nucleation above Certain Concentrations, J. Biol. Chem., 2010, 285, 34741-34745.

102 G. Vali, Interpretation of freezing nucleation experiments: singular and stochastic; sites and surfaces, Atmos. Chem. Phys., 2014, 14, 5271-5294.

103 T. Inada, T. Koyama, F. Goto and T. Seto, Inactivation of Ice Nucleating Activity of Silver Iodide by Antifreeze Proteins and Synthetic Polymers, J. Phys. Chem. B, 2012, 116, 5364-5371.

104 C. Holt, The effect of antifreeze proteins and poly(vinyl alcohol) on the nucleation of ice: a preliminary study, CryoLetters, 2003, 24, 323-330.

105 K. E. Zachariassen and J. A. Husby, Antifreeze effect of thermal hysteresis agents protects highly supercooled insects, Nature, 1982, 298, 865-867.

106 K. E. Zachariassen, A. L. DeVries, B. Hunt and E. Kristiansen, Effect of ice fraction and dilution factor on the antifreeze activity in the hemolymph of the cerambycid beetle Rhagium inquisitor, Cryobiology, 2002, 44, 132-141.

107 N. Kubota, Effects of cooling rate, annealing time and biological antifreeze concentration on thermal hysteresis reading, Cryobiology, 2011, 63, 198-209.
108 L. Chapsky and B. Rubinsky, Kinetics of antifreeze proteininduced ice growth inhibition, FEBS Lett., 1997, 412, 241-244.

109 N. Smolin and V. Daggett, Formation of ice-like water structure on the surface of an antifreeze protein, J. Phys. Chem. B, 2008, 112, 6193-6202.

110 D. R. Nutt and J. C. Smith, Dual Function of the Hydration Layer around an Antifreeze Protein Revealed by Atomistic Molecular Dynamics Simulations, J. Am. Chem. Soc., 2008, 130, 13066-13073.

111 J. Grabowska, A. Kuffel and J. Zielkiewicz, Structure of solvation water around the active and inactive regions of a type III antifreeze protein and its mutants of lowered activity, J. Chem. Phys., 2016, 145, 075101.

112 J. A. Raymond and A. L. DeVries, Adsorption inhibition as a mechanism of freezing resistance in polar fishes, Proc. Natl. Acad. Sci. U. S. A., 1977, 74, 2589-2593.

113 P. W. Wilson, A model for thermal hysteresis utilizing the anisotropic interfacial energy of ice crystals, Cryobiology, 1994, 31, 406-412.

114 C. A. Knight and A. Wierzbicki, Adsorption of biomolecules to ice and their effects upon ice growth. 2. A discussion of the basic mechanism of "antifreeze" phenomena, Cryst. Growth Des., 2001, 1, 439-446.

115 L. M. Sander and A. V. Tkachenko, Kinetic Pinning and Biological Antifreezes, Phys. Rev. Lett., 2004, 93, 128102.

116 Q. Z. Li and L. F. Luo, The kinetic-theory of thermal hysteresis of a macromolecule solution, Chem. Phys. Lett., 1993, 216, 453-457.

117 S. Grandum, et al., Analysis of ice crystal growth for a crystal surface containing adsorbed antifreeze proteins, J. Cryst. Growth, 1999, 205, 382-390.

118 S. Zepeda, E. Yokoyama, Y. Uda, C. Katagiri and Y. Furukawa, In situ observation of antifreeze glycoprotein kinetics at the ice interface reveals a two-step reversible adsorption mechanism, Cryst. Growth Des., 2008, 8, 3666-3672.

119 H. Hansen-Goos, E. S. Thomson and J. S. Wettlaufer, On the edge of habitability and the extremes of liquidity, Planet. Space Sci., 2014, 98, 169-181.

120 K. Meister, et al., Investigation of the Ice-Binding Site of an Insect Antifreeze Protein Using Sum-Frequency Generation Spectroscopy, J. Phys. Lett., 2015, 6, 1162-1167.

121 Y. Ba, J. Wongskhaluang and J. B. Li, Reversible binding of the HPLC6 isoform of type I antifreeze proteins to ice surfaces and the antifreeze mechanism studied by multiple quantum filtering-spin exchange NMR experiment, J. Am. Chem. Soc., 2003, 125, 330-331.

122 Y. Celik, et al., Microfluidic experiments reveal that antifreeze proteins bound to ice crystals suffice to prevent their growth, Proc. Natl. Acad. Sci. U. S. A., 2013, 110, 1309-1314.

123 R. Drori, P. L. Davies and I. Braslavsky, When Are Antifreeze Proteins in Solution Essential for Ice Growth Inhibition?, Langmuir, 2015, 31, 5805-5811.

124 C. A. Knight and A. L. DeVries, Ice growth in supercooled solutions of a biological "antifreeze", AFGP 1-5: an explanation in terms of adsorption rate for the concentration dependence 
of the freezing point, Phys. Chem. Chem. Phys., 2009, 11, 5749-5761.

125 B. L. Wilkinson, et al., Total Synthesis of Homogeneous Antifreeze Glycopeptides and Glycoproteins, Angew. Chem., Int. Ed., 2012, 51, 3606-3610.

126 M. Urbańczyk, J. Góra, R. Latajka and N. Sewald, Antifreeze glycopeptides: from structure and activity studies to current approaches in chemical synthesis, Amino Acids, 2017, 49, 209-222.

127 A. K. Balcerzak, C. J. Capicciotti, J. G. Briard and R. N. Ben, Designing ice recrystallization inhibitors: from antifreeze (glyco)proteins to small molecules, RSC Adv., 2014, 4, 42682-42696.

128 B. L. Pentelute, Z. P. Gates, J. L. Dashnau, J. M. Vanderkooi and S. B. H. Kent, Mirror image forms of snow flea antifreeze protein prepared by total chemical synthesis have identical antifreeze activities, J. Am. Chem. Soc., 2008, 130, 9702-9707.

129 N. Miller, G. M. Williams and M. A. Brimble, Synthesis of Fish Antifreeze Neoglycopeptides Using Microwave-Assisted “Click Chemistry”, Org. Lett., 2009, 11, 2409-2412.

130 R. Peltier, et al., Synthesis and antifreeze activity of fish antifreeze glycoproteins and their analogues, Chem. Sci., 2010, 1, 538-551.

131 P. Czechura, R. Y. Tam, E. Dimitrijevic, A. V. Murphy and R. N. Ben, The Importance of Hydration for Inhibiting Ice Recrystallization with C-Linked Antifreeze Glycoproteins, J. Am. Chem. Soc., 2008, 130, 2928-2929.

132 Y. Tachibana, et al., Antifreeze Glycoproteins: Elucidation of the Structural Motifs That Are Essential for Antifreeze Activity, Angew. Chem., 2004, 116, 874-880.

133 A. Eniade, A. V. Murphy, G. Landreau and R. N. Ben, A general synthesis of structurally diverse building blocks for preparing analogues of C-linked antifreeze glycoproteins, Bioconjugate Chem., 2001, 12, 817-823.

134 R. Y. Tam, et al., Solution Conformation of C-Linked Antifreeze Glycoprotein Analogues and Modulation of Ice Recrystallization, J. Am. Chem. Soc., 2009, 131, 15745-15753.

135 C. J. Capicciotti, et al., Small Molecule Ice Recrystallization Inhibitors Enable Freezing of Human Red Blood Cells with Reduced Glycerol Concentrations, Sci. Rep., 2015, 5, 9692.

136 S. M. Ghobadloo, et al., Carbohydrate-Based Ice Recrystallization Inhibitors Increase Infectivity and Thermostability of Viral Vectors, Sci. Rep., 2014, 4, 05903.

137 R. Y. Tam, S. S. Ferreira, P. Czechura, J. L. Chaytor and R. N. Ben, Hydration Index-A Better Parameter for Explaining Small Molecule Hydration in Inhibition of Ice Recrystallization, J. Am. Chem. Soc., 2008, 130, 17494-17501.

138 C. J. Capicciotti, et al., Potent inhibition of ice recrystallization by low molecular weight carbohydrate-based surfactants and hydrogelators, Chem. Sci., 2012, 3, 1408-1416.

139 T. Inada and S. S. Lu, Thermal hysteresis caused by nonequilibrium antifreeze activity of poly(vinyl alcohol), Chem. Phys. Lett., 2004, 394, 361-365.

140 T. Inada and S. S. Lu, Inhibition of recrystallization of ice grains by adsorption of poly(vinyl alcohol) onto ice surfaces, Cryst. Growth Des., 2003, 3, 747-752.
141 M. I. Gibson, C. A. Barker, S. G. Spain, L. Albertin and N. R. Cameron, Inhibition of Ice Crystal Growth by Synthetic Glycopolymers: Implications for the Rational Design of Antifreeze Glycoprotein Mimics, Biomacromolecules, 2009, 10, 328-333.

142 W. Zhang and R. A. Laursen, Artificial antifreeze polypeptides: alpha-helical peptides with KAAK motifs have antifreeze and ice crystal morphology modifying properties, FEBS Lett., 1999, 455, 372-376.

143 A. Wierzbicki, et al., Structure-function relationship in the antifreeze activity of synthetic alanine-lysine antifreeze polypeptides, Biomacromolecules, 2000, 1, 268-274.

144 M. L. Huang, et al., Biomimetic peptoid oligomers as dualaction antifreeze agents, Proc. Natl. Acad. Sci. U. S. A., 2012, 109, 19922-19927.

145 D. Crich and M. Y. Rahaman, Synthesis and Structural Verification of the Xylomannan Antifreeze Substance from the Freeze-Tolerant Alaskan Beetle Upis ceramboides, J. Org. Chem., 2011, 76, 8611-8620.

146 O. Mizrahy, M. Bar-Dolev, S. Guy and I. Braslavsky, Inhibition of Ice Growth and Recrystallization by Zirconium Acetate and Zirconium Acetate Hydroxide, PLoS One, 2013, 8, e59540.

147 S. Deville, et al., Ice Shaping Properties, Similar to That of Antifreeze Proteins, of a Zirconium Acetate Complex, PLoS One, 2011, 6, e26474.

148 H. Geng, et al., Graphene Oxide Restricts Growth and Recrystallization of Ice Crystals, Angew. Chem., Int. Ed., 2016, 56, 997-1001.

149 R. Drori, et al., A Supramolecular Ice Growth Inhibitor, J. Am. Chem. Soc., 2016, 138, 13396-13401.

150 C. James, G. Purnell and S. J. James, A Review of Novel and Innovative Food Freezing Technologies, Food Bioprocess Technol., 2015, 8, 1616-1634.

151 A. Regand and H. D. Goff, Ice recrystallization inhibition in ice cream as affected by ice structuring proteins from winter wheat grass, J. Dairy Sci., 2006, 89, 49-57.

152 C. J. Clarke, S. L. Buckley and N. Lindner, Ice structuring proteins - a new name for antifreeze proteins, CryoLetters, 2002, 23, 89-92.

153 W. Boonsupthip and T. C. Lee, Application of antifreeze protein for food preservation: Effect of type III antifreeze protein for preservation of gel-forming of frozen and chilled actomyosin, J. Food Sci., 2003, 68, 1804-1809.

154 S. R. Payne and O. A. Young, Effects of pre-slaughter administration of antifreeze proteins on frozen meat quality, Meat Sci., 1995, 41, 147-155.

155 C. M. Yeh, B. Y. Kao and H. J. Peng, Production of a Recombinant Type 1 Antifreeze Protein Analogue by L. lactis and Its Applications on Frozen Meat and Frozen Dough, J. Agric. Food Chem., 2009, 57, 6216-6223.

156 A. Margaritis and A. S. Bassi, Principles and biotechnological applications of bacterial ice nucleation, Crit. Rev. Biotechnol., 1991, 11, 277-295.

157 http:/www.fda.gov/AnimalVeterinary/DevelopmentApproval Process/GeneticEngineering/GeneticallyEngineeredAnimals/ ucm280853.htm. 
158 G. Neelakanta, A. M. Hudson, H. Sultana, L. Cooley and E. Fikrig, Expression of Ixodes scapularis Antifreeze Glycoprotein Enhances Cold Tolerance in Drosophila melanogaster, PLoS One, 2012, 7, e33447.

159 H. K. Khanna and G. E. Daggard, Targeted expression of redesigned and codon optimised synthetic gene leads to recrystallisation inhibition and reduced electrolyte leakage in spring wheat at sub-zero temperatures, Plant Cell Rep., 2006, 25, 1336-1346.

160 M. Heisig, et al., Frostbite Protection in Mice Expressing an Antifreeze Glycoprotein, PLoS One, 2015, 10, 0116562.

$161 \mathrm{H}$. Bagis, et al., Stable transmission and transcription of Newfoundland ocean pout type III fish antifreeze protein (AFP) gene in transgenic mice and hypothermic storage of transgenic ovary and testis, Mol. Reprod. Dev., 2006, 73, 1404-1411.

162 O. Le Curieux-Belfond, L. Vandelac, J. Caron and G. E. Seralini, Factors to consider before production and commercialization of aquatic genetically modified organisms: the case of transgenic salmon, Environ. Sci. Policy, 2009, 12, 170-189.

163 A. Sapkota, et al., Aquaculture practices and potential human health risks: current knowledge and future priorities, Environ. Int., 2008, 34, 1215-1226.

$164 \mathrm{~J}$. Bakhach, The cryopreservation of composite tissues: principles and recent advancement on cryopreservation of different type of tissues, Organogenesis, 2009, 5, 119-126.

165 A. V. Makarevich, et al., Several aspects of animal embryo cryopreservation: anti-freeze protein (AFP) as a potential cryoprotectant, Zygote, 2010, 18, 145-153.

$166 \mathrm{~J}$. L. Chaytor, et al., Inhibiting ice recrystallization and optimization of cell viability after cryopreservation, Glycobiology, 2012, 22, 123-133.

167 J. Huebinger, et al., Direct Measurement of Water States in Cryopreserved Cells Reveals Tolerance toward Ice Crystallization, Biophys. J., 2016, 110, 840-849.

168 D. K. Hincha, A. L. Devries and J. M. Schmitt, Cryotoxicity of antifreeze proteins and glycoproteins to spinach thylakoid membranes - comparison with cryotoxic sugar acids, Biochim. Biophys. Acta, 1993, 1146, 258-264.

169 G. Amir, et al., Prolonged 24 hour subzero preservation of heterotopically transplanted rat hearts using antifreeze proteins derived from arctic fish, Ann. Thorac. Surg., 2004, 77, 1648-1655.

170 C. J. Capicciotti, M. Doshi and R. N. Ben, Ice Recrystallization Inhibitors: From Biological Antifreezes to Small Molecules, 2013.

171 B. Wowk, et al., Vitrification enhancement by synthetic ice blocking agents, Cryobiology, 2000, 40, 228-236.

172 A. Ideta, et al., Prolonging hypothermic storage (4 C) of bovine embryos with fish antifreeze protein, J. Reprod. Dev., 2015, 61, 1-6.

173 J. G. Briard, et al., Small molecule ice recrystallization inhibitors mitigate red blood cell lysis during freezing, transient warming and thawing, Sci. Rep., 2016, 6, 23619.

174 D. F. Chaves, et al., The use of antifreeze protein type III for vitrification of in vitro matured bovine oocytes, Cryobiology, 2016, 73, 324-328.
175 D. Lagneaux, M. Huhtinen, E. Koskinen and E. Palmer, Effect of anti-freeze protein (AFP) on the cooling and freezing of equine embryos as measured by DAPI-staining, Equine Vet. J., 1997, 29, 85-87.

176 T. Wang, Q. Zhu, X. Yang, J. R. Layne Jr and A. L. Devries, Antifreeze Glycoproteins from Antarctic Notothenioid Fishes Fail to Protect the Rat Cardiac Explant during Hypothermic and Freezing Preservation, Cryobiology, 1994, 31, 185-192.

177 J. A. Mugnano, T. Wang, J. R. Layne, A. L. DeVries and R. E. Lee, Antifreeze glycoproteins promote intracellular freezing of rat cardiomyocytes at high subzero temperatures, Am. J. Physiol.: Regul., Integr. Comp. Physiol., 1995, 269, R474-R479.

178 H. Koushafar, L. Pham, C. Lee and B. Rubinsky, Chemical adjuvant cryosurgery with antifreeze proteins, J. Surg. Oncol., 1997, 66, 114-121.

179 S. Venketesh and C. Dayananda, Properties, potentials, and prospects of antifreeze proteins, Crit. Rev. Biotechnol., 2008, 28, 57-82.

180 Y. Hirano, et al., Hypothermic preservation effect on mammalian cells of type III antifreeze proteins from notched-fin eelpout, Cryobiology, 2008, 57, 46-51.

181 J. H. Wu, et al., Laboratory-scale extraction and characterization of ice-binding sericin peptides, Eur. Food Res. Technol., 2013, 236, 637-646.

182 J. W. Jo, B. C. Jee, C. S. Suh and S. H. Kim, The Beneficial Effects of Antifreeze Proteins in the Vitrification of Immature Mouse Oocytes, PLoS One, 2012, 7, e37043.

183 L. Zilli, et al., Comparative Proteome Analysis of Cryopreserved Flagella and Head Plasma Membrane Proteins from Sea Bream Spermatozoa: Effect of Antifreeze Proteins, PLoS One, 2014, 9, e99992.

184 S. G. Lee, H. Y. Koh, J. H. Lee, S. H. Kang and H. J. Kim, Cryopreservative Effects of the Recombinant Ice-Binding Protein from the Arctic Yeast Leucosporidium sp on Red Blood Cells, Appl. Biochem. Biotechnol., 2012, 167, 824-834.

185 J. Lee, et al., Effects of Three Different Types of Antifreeze Proteins on Mouse Ovarian Tissue Cryopreservation and Transplantation, PLoS One, 2015, 10, 0126252.

186 G. Amir, et al., Subzero nonfreezing cryopresevation of rat hearts using antifreeze protein I and antifreeze protein III, Cryobiology, 2004, 48, 273-282.

187 A. I. Younis, B. Rooks, S. Khan and K. G. Gould, The effects of antifreeze peptide III (AFP) and insulin transferrin selenium (ITS) on cryopreservation of chimpanzee (Pan troglodytes) spermatozoa, J. Androl., 1998, 19, 207-214.

188 K. Matsumura and S. H. Hyon, Polyampholytes as low toxic efficient cryoprotective agents with antifreeze protein properties, Biomaterials, 2009, 30, 4842-4849.

189 R. C. Deller, M. Vatish, D. A. Mitchell and M. I. Gibson, Synthetic polymers enable non-vitreous cellular cryopreservation by reducing ice crystal growth during thawing, Nat. Commun., 2014, 5, 3244.

190 M. Leclere, B. K. Kwok, L. K. Wu, D. S. Allan and R. N. Ben, C-Linked Antifreeze Glycoprotein (C-AFGP) Analogues as 
Novel Cryoprotectants, Bioconjugate Chem., 2011, 22, 1804-1810.

191 S. H. Liu, et al., In vitro studies of antifreeze glycoprotein (AFGP) and a C-Linked AFGP analogue, Biomacromolecules, 2007, 8, 1456-1462.

192 M. Fukushima, S. Tsuda and Y. Yoshizawa, Fabrication of Highly Porous Alumina Prepared by Gelation Freezing Route with Antifreeze Protein, J. Am. Ceram. Soc., 2013, 96, 1029-1031.

193 M. Heisig, et al., Antivirulence Properties of an Antifreeze Protein, Cell Rep., 2014, 9, 417-424.

194 T. Koop and B. Zobrist, Parameterizations for ice nucleation in biological and atmospheric systems, Phys. Chem. Chem. Phys., 2009, 11, 10839-10850.

195 B. G. Pummer, et al., Ice nucleation by water-soluble macromolecules, Atmos. Chem. Phys., 2015, 15, 4077-4091.

196 G. Petzold and J. M. Aguilera, Ice Morphology: Fundamentals and Technological Applications in Foods, Food Biophys., 2009, 4, 378-396.

197 X. Wen, et al., Antifreeze proteins govern the precipitation of trehalose in a freezing-avoiding insect at low temperature, Proc. Natl. Acad. Sci. U. S. A., 2016, 113, 6683-6688.

198 S. Wang, X. Wen, P. Nikolovski, V. Juwita and J. F. Arifin, Expanding the molecular recognition repertoire of antifreeze polypeptides: effects on nucleoside crystal growth, Chem. Commun., 2012, 48, 11555-11557.
199 S. Wang, et al., Molecular Recognition of Methyl alpha-DMannopyranoside by Antifreeze (Glyco)Proteins, J. Am. Chem. Soc., 2014, 136, 8973-8981.

200 Y. Gwak, et al., Creating Anti-icing Surfaces via the Direct Immobilization of Antifreeze Proteins on Aluminum, Sci. Rep., 2015, 5, 1-9.

201 T. V. J. Charpentier, A. Neville, P. Millner, R. Hewson and A. Morina, An Investigation of Freezing of Supercooled Water on Anti-Freeze Protein Modified Surfaces, J. Bionic Eng., 2013, 10, 139-147.

202 H. C. Jung, J. M. Lebeault and J. G. Pan, Surface display of Zymomonas mobilis levansucrase by using the ice-nucleation protein of Pseudomonas syringae, Nat. Biotechnol., 1998, 16, 576-580.

203 W. Chen and G. Georgiou, Cell-surface display of heterologous proteins: from high-throughput screening to environmental applications, Biotechnol. Bioeng., 2002, 79, 496-503.

204 H. Wernerus and S. Stahl, Biotechnological applications for surface-engineered bacteria, Biotechnol. Appl. Biochem., 2004, 40, 209-228.

205 L. A. Graham and P. L. Davies, Glycine-rich antifreeze proteins from snow fleas, Science, 2005, 310, 461.

$206 \mathrm{~S}$. O. Yu, et al., Ice restructuring inhibition activities in antifreeze proteins with distinct differences in thermal hysteresis, Cryobiology, 2010, 61, 327-334. 